\title{
Validation of Aura Microwave Limb Sounder OH measurements with Fourier Transform Ultra-Violet Spectrometer total OH column measurements at Table Mountain, California
}

\author{
Shuhui Wang, ${ }^{1}$ Herbert M. Pickett, ${ }^{1}$ Thomas J. Pongetti, ${ }^{1}$ Ross Cheung, ${ }^{2}$ Yuk L. Yung, ${ }^{2}$ \\ Changsub Shim, ${ }^{1}$ Qinbin Li, ${ }^{1}$ Timothy Canty, ${ }^{3}$ Ross J. Salawitch, ${ }^{4}$ Kenneth W. Jucks, ${ }^{5}$ \\ Brian Drouin, ${ }^{1}$ and Stanley P. Sander ${ }^{1}$ \\ Received 29 January 2008; revised 15 August 2008; accepted 26 August 2008; published 19 November 2008.
}

[1] The first seasonal and interannual validation of $\mathrm{OH}$ measurements from the Aura Microwave Limb Sounder (MLS) has been conducted using ground-based $\mathrm{OH}$ column measurements from the Fourier Transform Ultra-Violet Spectrometer (FTUVS) over the Jet Propulsion Laboratory's Table Mountain Facility (TMF) during 2004-2007. To compare with FTUVS total column measurements, MLS OH vertical profiles over TMF are integrated to obtain partial $\mathrm{OH}$ columns above $21.5 \mathrm{hPa}$, which covers nearly $90 \%$ of the total column. The tropospheric $\mathrm{OH}$ and the lower stratopheric $\mathrm{OH}$ not measured by MLS are estimated using GEOS (Goddard Earth Observing System)-Chem and a Harvard 2-D model implemented within GEOS-Chem, respectively. A number of field observations and calculations from a photochemical box model are compared to $\mathrm{OH}$ profiles from these models to estimate the variability in the lower atmospheric $\mathrm{OH}$ and thus the uncertainty in the combined total OH columns from MLS and models. In general, the combined total $\mathrm{OH}$ columns agree extremely well with TMF total $\mathrm{OH}$ columns, especially during seasons with high $\mathrm{OH}$. In winter with low $\mathrm{OH}$, the combined columns are often higher than TMF measurements. A slightly weaker seasonal variation is observed by MLS relative to TMF. OH columns from TMF and the combined total columns from MLS and models are highly correlated, resulting in a mean slope of 0.969 with a statistically insignificant intercept. This study therefore suggests that column abundances derived from MLS vertical profiles have been validated to within the mutual systematic uncertainties of the MLS and FTUVS measurements.

Citation: Wang, S., et al. (2008), Validation of Aura Microwave Limb Sounder OH measurements with Fourier Transform Ultra-Violet Spectrometer total OH column measurements at Table Mountain, California, J. Geophys. Res., 113, D22301, doi:10.1029/2008JD009883.

\section{Introduction}

[2] Ozone in the stratosphere and the lower mesosphere plays an important role in regulating the temperature and circulation of the global stratosphere [e.g., Müller et al., 1999]. While halogen species are mainly responsible for ozone depletion [e.g., Müller et al., 1999] near $40 \mathrm{~km}$,

\footnotetext{
${ }^{1}$ Jet Propulsion Laboratory, California Institute of Technology, Pasadena, California, USA.

${ }^{2}$ Division of Geological and Planetary Sciences, California Institute of Technology, Pasadena, California, USA.

${ }^{3}$ Department of Atmospheric and Oceanic Science, University of Maryland, College Park, Maryland, USA.

${ }^{4}$ Department of Atmospheric and Oceanic Science and Department of Chemistry and Biochemistry, University of Maryland, College Park, Maryland, USA.

${ }^{5}$ Harvard-Smithsonian Center for Astrophysics, Cambridge, Massachusetts, USA.
}

Copyright 2008 by the American Geophysical Union. 0148-0227/08/2008JD009883\$09.00 above $40 \mathrm{~km}$ and below $22 \mathrm{~km}$ the major catalytic ozone loss is controlled by reactions involving odd hydrogen species $\mathrm{HO}_{x}$ [Osterman et al., 1997; Salawitch et al., 2005]. These reactions are the dominant loss process for ozone in the upper stratosphere and mesosphere, a region for which the balance between photochemical production and loss of ozone [e.g., Canty et al., 2006] is a subject of continued scientific study. Since $\mathrm{OH}$ is so intimately linked to upper stratospheric and mesospheric ozone, it is essential to obtain systematic and long-term measurements of $\mathrm{OH}$.

[3] The NASA Aura satellite was launched on 15 July 2004 into a sun-synchronous orbit. The Earth Observing System (EOS) Microwave Limb Sounder (MLS) onboard Aura has been providing measurements of a number of chemical species including $\mathrm{OH}$ for over 3 years [Waters et al., 2006; Pickett, 2006].

[4] Early validation of MLS measurements for several molecules was reported in [Froidevaux et al., 2006]. The validation of $\mathrm{OH}$ measurements was conducted for a short period in September 2004 with data acquired by the Balloon 
$\mathrm{OH}$ instrument $(\mathrm{BOH})$ and Far Infrared Spectrometer (FIRS-2), both launched from Fort Sumner, New Mexico [Pickett et al., 2006]. It was found that the $\mathrm{OH}$ columns above $40 \mathrm{~km}$ from these measurements agreed within $8 \%$, while the $\mathrm{OH}$ densities at $25-40 \mathrm{~km}$ altitudes agreed within $17 \%$. The version 1.51 retrieval software was used.

[5] More recently, MLS $\mathrm{HO}_{x}$ data products from version 2.2 software, which are significantly improved compared with version 1.51 for mesospheric $\mathrm{OH}$ and stratospheric $\mathrm{HO}_{2}$, were validated for two days of data: 23 September 2004 and 20 September 2005 [Pickett et al., 2008]. The updated MLS OH results agree with the BOH and FIRS-2 measurements within $15 \%$ and $18 \%$ at $25-40 \mathrm{~km}$ altitudes for those two dates, respectively. Results from a photochemical box model constrained with $\mathrm{OH}$ precursors (i.e., $\mathrm{H}_{2} \mathrm{O}$ and $\mathrm{O}_{3}$ ) measured by MLS also agree with MLS OH profiles to within the MLS measurement precision [Pickett et al., 2008]. Validation for other times of year, however, has not yet been reported. Most importantly, with the exception of a figure by Pickett et al. [2008] that shows comparisons for a single day, there has been no report on the comparison between $\mathrm{OH}$ measurements from MLS and from ground-based instruments.

[6] The Jet Propulsion Laboratory's Fourier Transform Ultra-Violet Spectrometer (FTUVS) instrument has been providing reliable ground-based total $\mathrm{OH}$ column measurements at the Table Mountain Facility (TMF) in southern California $\left(34.4^{\circ} \mathrm{N}, 117.7^{\circ} \mathrm{W}\right)$, under clear and lightly cloudy conditions, for the past decade [Cageao et al., 2001; Li et al., 2005; Mills et al., 2002, 2003]. During 2004-2007, there are 40 overlapping days with both MLS and TMF $\mathrm{OH}$ measurements and 76 additional cases with the two measurements one day apart, which offer an excellent opportunity to validate the seasonal and interannual variation of MLS OH data by comparing the $\mathrm{OH}$ columns from both measurements. The number of days available for comparison was limited by the processing state of the MLS v. 2.2 data at the time of the present study. Although MLS OH density measurements have useable precision only above about $25 \mathrm{~km}$, the $\mathrm{OH}$ column data from MLS measurements cover nearly $90 \%$ of the total $\mathrm{OH}$ abundance in the atmosphere. $\mathrm{OH}$ in the lower stratosphere and the troposphere, on the order of $10 \%$ of the total $\mathrm{OH}$ column abundance, has to be estimated by an independent method in order to compare the total $\mathrm{OH}$ columns from MLS and TMF.

[7] In the present work, the partial $\mathrm{OH}$ column (between the surface and $21.5 \mathrm{hPa}$ ) is estimated on the basis of $\mathrm{OH}$ profiles derived from the GEOS (Goddard Earth Observing System)-Chem model (for the troposphere) and the Harvard 2-D model (between the tropopause and $21.5 \mathrm{hPa}$ ). We also compare with observations from various other instruments and calculations from a constrained photochemical box model [Canty et al., 2006] to estimate the uncertainty of the lower atmospheric $\mathrm{OH}$ from the model, particularly for the lower stratosphere. The estimated lower atmospheric $\mathrm{OH}$ is combined with the MLS OH data to obtain a total $\mathrm{OH}$ column at latitudes and longitudes similar to TMF, which is then compared to the TMF $\mathrm{OH}$ column data at the Aura satellite overpass time. The overall agreement and the agreement at various seasons and solar zenith angles
(SZA) are quantified. Possible causes of differences are discussed.

\section{Experimental Techniques and Model Description}

\subsection{Microwave Limb Sounder on Aura}

[8] The MLS instrument contains heterodyne radiometers that observe thermal emission radiances from the atmospheric limb in five spectral regions continuously during day and night. $\mathrm{OH}$ is measured at $2.5 \mathrm{THz}$ in the stratosphere and mesosphere. The daytime measurements are corrected by the nighttime measurements to eliminate the instrument offset. The bias uncertainty is minimized when the day-night differences are taken [Pickett et al., 2006, 2008]. This is recommended for $\mathrm{OH}$ data at pressures $\geq 10 \mathrm{hPa}$. Since the nighttime concentrations of $\mathrm{OH}$ for $10-0.1 \mathrm{hPa}$ are less than $1 \%$ of typical noontime $\mathrm{OH}$ densities, no such correction is applied for pressure $<10 \mathrm{hPa}$. A detailed description of the $\mathrm{OH}$ retrieval technique and the instrument calibration is given by Pickett [2006]. The sources of systematic uncertainties from instrumental issues include radiometric calibration, field of view characterization, spectroscopic uncertainty, and approximations in the retrieval formulation and implementation. In the most recent validation study, the systematic errors for $\mathrm{OH}$ measurements were estimated to be less than $8 \%$ over $32-$ $0.003 \mathrm{hPa}$ [Pickett et al., 2008].

[9] The $\mathrm{OH}$ products used in this study are from v2.2 retrieval software unless otherwise specified. The difference between v2.2 and the previous version v1.51 for $\mathrm{OH}$ are discussed by Pickett et al. [2008]. For validation purposes, MLS OH data at a latitude range $\left[29.5^{\circ} \mathrm{N}, 39.5^{\circ} \mathrm{N}\right]$ and a longitude range $\left[130.15^{\circ} \mathrm{W}, 105.15^{\circ} \mathrm{W}\right]$ were extracted for selected days. Because of their poor precision in the lower atmosphere as a result of water vapor absorption, $\mathrm{OH}$ densities below $21.5 \mathrm{hPa}$ were not considered. The extracted $\mathrm{OH}$ data were integrated vertically to obtain partial $\mathrm{OH}$ columns from $21.5 \mathrm{hPa}$ to the upper mesosphere.

[10] The Aura satellite is in a sun-synchronous orbit. The time when the MLS field of view scans the latitudes and longitudes covering TMF is often between 2100-2130 UT with a small variation from day to day. To be accurate, the SZA is used as the primary criterion to match the TMF data points with the MLS measurements for any given day.

\subsection{High-Resolution Fourier Transform Ultra-Violet Spectrometer at TMF}

[11] The FTUVS instrument has been used to measure the total OH column abundance over TMF since July 1997. Reliable data are obtained during days with clear to partially cloudy conditions. Cageao et al. [2001] provided a detailed description of the instrument system and the data retrieval process. The key $\mathrm{OH}$ absorption lines fall in the region of strong solar Fraunhofer lines, necessitating the use of a solar line suppression method. In this method, the FTUVS telescope alternately views the Sun's east and west limbs. The Doppler shift between the east and west limb spectra due to solar rotation $\left(0.28 \mathrm{~cm}^{-1}\right)$ is used to separate terrestrial $\mathrm{OH}$ lines from the strong solar lines. As part of the retrieval, the west limb spectra are shifted to match the east limb spectra. By dividing the east spectra by the shifted 
Table 1. Side-by-Side Comparison of the Two Versions of GEOS-Chem Used in This Study

\begin{tabular}{|c|c|c|}
\hline & 2003 Monthly Mean & 2005 Hourly Outputs \\
\hline Model version & V5-07-08 & V7-04-10 \\
\hline Meteorology & GEOS-3 meteorology from 2001 & Current GEOS-4 meteorology \\
\hline Horizontal resolution & $\begin{array}{l}\text { Results were regridded into GEOS-4 } \\
\text { resolution }(2 \times 2.5)\end{array}$ & GEOS-4 resolution $(2 \times 2.5)$ \\
\hline Vertical resolution & 55 layers & 30 layers \\
\hline Emissions & $\begin{array}{l}\text { The major emissions (fossil fuel, } \\
\text { biomass burning, etc.) are the same }\end{array}$ & $\begin{array}{l}\text { The major emissions (fossil fuel, } \\
\text { biomass burning, etc.) are the same }\end{array}$ \\
\hline
\end{tabular}

west spectra, the solar features are attenuated by a factor of 10-100 with minimal perturbation of the terrestrial $\mathrm{OH}$ lines. Given a modeled Doppler broadened $\mathrm{OH}$ line shape, the corresponding absorption cross section, and the measured air mass factor, the $\mathrm{OH}$ column abundance is retrieved from the spectral fit. A typical measurement cycle takes about 30 min ( 15 min for each limb).

[12] The primary source of uncertainties in the measured $\mathrm{OH}$ column is the spectral fit [Cageao et al., 2001; Li et al., 2005]. A number of improvements to the spectral analysis program were made very recently, leading to a significant decrease in the spectral fit uncertainties [Cheung et al., 2008]. A Fast Fourier Transform (FFT) smoothing technique is adopted to describe the remaining broadband solar background feature in the East/West ratio spectra. This allows for a further correction of the background curvature prior to the $\mathrm{OH}$ line fit. A conjugate-gradient fit, which is more efficient than the traditional shift-and-scale fit, is employed over a much narrower spectral window (nanowindow) selected empirically. The FFT correction of the solar baseline combined with the conjugate-gradient fit significantly improves the spectral fit quality [Cheung et al., 2008]. In particular, the spectral fit quality of several weak $\mathrm{OH}$ lines has been greatly improved so that a more reliable multiple-absorption line analysis can be used to further improve the precision. Previously, only the $P_{1}(1)$ line $\left(32440.57 \mathrm{~cm}^{-1}\right)$ was analyzed because it is a strong line with the least influence from the solar baseline curvature. Mills et al. [2002, 2003] adopted $Q_{1}(2)$ as an additional line and showed an acceptable agreement between $\mathrm{OH}$ retrieved with $Q_{1}(2)$ and $P_{1}(1)$ lines. Li et al. [2005] further expanded the analysis to five $\mathrm{OH}$ lines and used the diurnal variability as a weighting factor to average the results. Unlike the previous multiline analysis techniques, the current retrieval introduces an advanced "dynamic line selection," which accepts $\mathrm{OH}$ lines that reduce the deviation of the weighted average from a second-order polynomial fit of the diurnal variation but rejects lines that merely contribute more random noise. The weighted average is based on the signal-to-noise ratio (SNR) of each selected absorption line. SNR is shown to be more reliable than the previously adopted weighting factors since it takes both the quality of the signal and the quality of the spectral fit into account without making assumptions about the diurnal variation pattern [Cheung et al., 2008].

[13] The major source of systematic errors is the uncertainty in the $\mathrm{OH}$ line center absorption cross section, which is introduced primarily by the uncertainty in the measured lifetime of the $\mathrm{OH}$ vibrational level. The resulting systematic error was estimated to be $\pm 10 \%$ [Cageao et al., 2001; Li et al., 2005].
[14] Since the MLS overpass time is close to local noon, $\mathrm{OH}$ line signals around overpass time are generally strong and of good quality. During most clear summer days, five $\mathrm{OH}$ lines are averaged, while only the three strongest lines are dynamically selected during a typical winter day. In several extreme cases with particularly weak $\mathrm{OH}$ signals even around noon time, only results from $P_{1}(1)$ and $Q_{1}(2)$ contribute to the weighted average.

\subsection{GEOS-Chem Model Description}

[15] GEOS-Chem is a global 3-D chemical transport model driven by assimilated meteorological data from the NASA Global Modeling Assimilation Office (GMAO). A comprehensive tropospheric $\mathrm{O}_{3}-\mathrm{NO}_{x}$-VOC chemistry mechanism is included. Detailed model description and evaluation are given by Bey et al. [2001]. GEOS-Chem has been extensively evaluated and used to study a variety of atmospheric phenomena. It has proven to be a useful tool for studying the global tropospheric distribution of $\mathrm{OH}[$ Bloss et al., 2005].

[16] In this study, GEOS-Chem 2003 monthly mean OH products are used to estimate the small partial $\mathrm{OH}$ column from the surface to $21.5 \mathrm{hPa}$ at TMF, which is on the order of $10 \%$ of the total $\mathrm{OH}$ abundance. Since GEOS-Chem only models tropospheric chemistry, a Harvard 2-D model [Schneider et al., 2000] is implemented within this version of GEOS-Chem (v5-07-08) to calculate $\mathrm{OH}$ in the lower stratosphere. The tropospheric and lower stratospheric $\mathrm{OH}$ each contributes about $5 \%$ to the total $\mathrm{OH}$ abundance. Photochemical box model calculations in combination with field observations are compared to the GEOS-Chem results to evaluate this approach and to quantify the uncertainty of the lower atmospheric $\mathrm{OH}$ estimates. The details are discussed in section 3.3.

[17] In the present work, the version v7-04-10 of GEOSChem with hourly $\mathrm{OH}$ outputs is also used to calculate TMF tropospheric $\mathrm{OH}$ at satellite overpass time to compare with data derived from GEOS-Chem 2003 monthly mean products (v5-07-08) (see http://www.as.harvard.edu/chemistry/trop/ geos/geos_versions.html for version history). The major differences between these versions are listed in Table 1 . The 3-D meteorological fields are updated every six hours. The surface fields and mixing depths are updated every three hours. Climatological monthly mean biomass burning emissions are from Duncan et al. [2003]. The emission inventory of v5-07-08 is from the Global Emission Inventory Activity (GEIA). In v7-04-10, the fossil fuel emissions for $\mathrm{NO}_{x}, \mathrm{CO}$, and $\mathrm{SO}_{2}$ are from the Emission Database for Global Atmospheric Research (EDGAR), while the emission inventory for the other species are from GEIA [Benkovitz et al., 1996; Olivier and Berdowski, 2001]. For the model grid that covers 

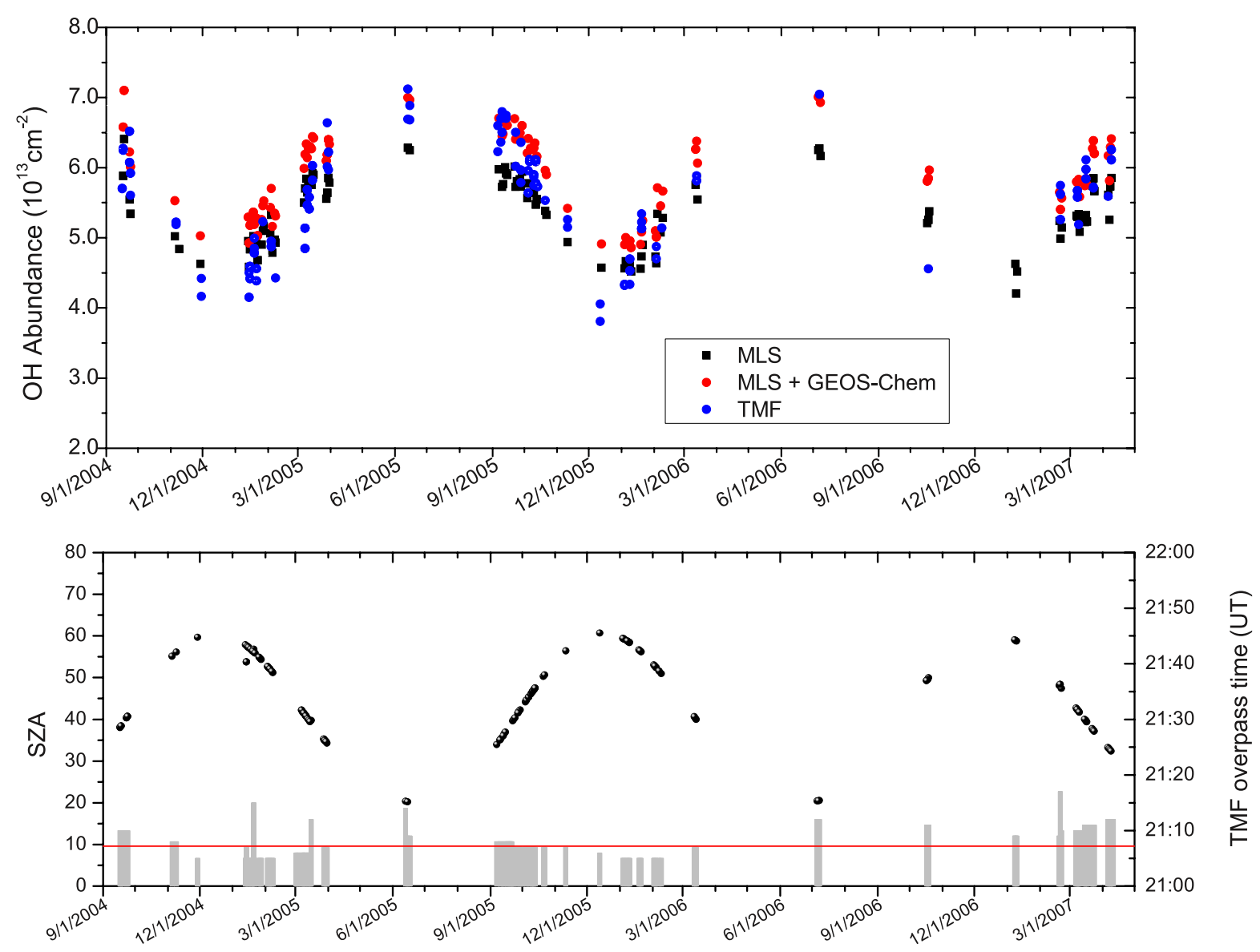

Figure 1. OH column results from MLS, MLS + GEOS-Chem, and TMF. (top) Black squares indicate MLS partial $\mathrm{OH}$ columns above $21.5 \mathrm{hPa}$. The total $\mathrm{OH}$ column from the sum of MLS and GEOS-Chem partial $\mathrm{OH}$ columns are shown in red circles. Blue circles are the TMF total $\mathrm{OH}$ abundance. (bottom) The SZA of MLS measurements is plotted. The corresponding overpass time at TMF area is plotted as gray vertical bars. The average overpass time is about 2107 UT, marked with the red horizontal line.

TMF, the major source of $\mathrm{OH}$ in the boundary layer is believed to be the anthropogenic emissions. Biomass burning also plays a role in the mountain areas during dry seasons. In the upper troposphere, the long-range transport is a major factor influencing $\mathrm{OH}$ distributions.

[18] The $2^{\circ} \times 2.5^{\circ}$ model grid covering TMF has a latitude range of $\left[33.0^{\circ} \mathrm{N}, 35.0^{\circ} \mathrm{N}\right]$ and a longitude range of $\left[117.5^{\circ} \mathrm{W}\right.$, $\left.120.0^{\circ} \mathrm{W}\right]$, a significant part of which is over the Pacific ocean. The average elevation in the model grid is thus lower than the elevation of TMF $(2.25 \mathrm{~km})$. This difference is taken into account in the calculation of $\mathrm{OH}$ columns over TMF, and is discussed in detail in section 3.2.

\section{Results}

\subsection{MLS Partial OH Column and TMF Total OH Column}

[19] The MLS v2.2 partial OH columns above $21.5 \mathrm{hPa}$ (i.e., for pressures less than $21.5 \mathrm{hPa}$ ) over TMF on selected days during 2004-2007 are plotted in Figure 1 (black points). The $\mathrm{OH}$ columns in all figures are vertical columns. For a close comparison, the selection only includes days when TMF measurements are available on the same day or one day away. The SZA of MLS measurements are plotted in Figure 1 (bottom). The corresponding time at the location of TMF was calculated with the Multiyear Interactive Computer Almanac (MICA) from the U.S. Naval Observatory. The calculated "overpass time" is between 21052117 UT with a mean of 2107 UT. Since the overpass time has a small variation from day to day, it is more accurate to use SZA as the criterion to select TMF data points for a comparison with MLS data.

[20] As described in section 2.2, a typical FTUVS measurement cycle takes about $30 \mathrm{~min}$, during which the SZA is changing. As a result of this measurement sequence, for every MLS SZA, there are typically two bracketing TMF measurements. For example, if an MLS measurement occurred at a SZA at which FTUVS was taking the $n$th west limb measurement, $\operatorname{West}(n)$, the TMF OH data out of two pairs of spectra, $\operatorname{East}(n-1) / \operatorname{West}(n)$ and $\operatorname{East}(n) /$ West $(n)$, were selected to compare with the MLS results. Only when the SZA occurred during the FTUVS telescope adjustment between two limbs, was there exactly one pair of spectra and thus one TMF data point to be selected. The corresponding TMF total $\mathrm{OH}$ abundance results during selected days are plotted in Figure 1 (top) (blue solid points). The large gaps in the time series of MLS data are 


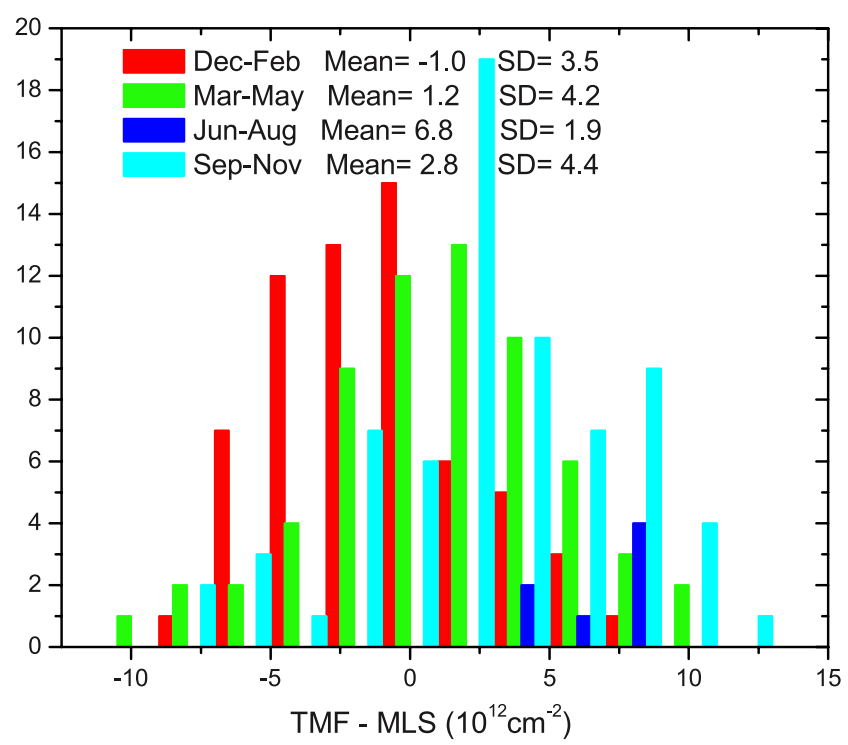

Figure 2. Histogram of the difference between TMF total $\mathrm{OH}$ column and MLS partial OH column. The selected days during 2004-2007 are grouped into four seasons. The vertical bars show the frequency of the occurrence of the corresponding difference between the observations during the specific season. The mean and the standard deviation (SD) values for all seasons are summarized.

due to the limited availability of processed MLS v2.2 data at the time of this study.

[21] Interestingly, during days with high $\mathrm{OH}$ levels the TMF total $\mathrm{OH}$ column is generally higher than the MLS partial column, leaving a positive difference that can be associated with the residual $\mathrm{OH}$ in the lower atmosphere. During winter days with low $\mathrm{OH}$, however, the partial $\mathrm{OH}$ column from MLS is often similar to or even higher than the TMF total $\mathrm{OH}$ column, resulting in a negligible or even slightly negative difference. This would imply the presence of no residual $\mathrm{OH}$ in the lower atmosphere, which is unlikely. A seasonal histogram of this residual $\mathrm{OH}$ clearly illustrates this seasonal effect (Figure 2). The highest $\mathrm{OH}$ residual occurs in summer $\left(4.3 \times 10^{12}-8.8 \times 10^{12} \mathrm{~cm}^{-2}\right)$. The fall data set, with the majority of data in September, shows smaller mean $\mathrm{OH}$ residual $\left(2.8 \times 10^{12} \mathrm{~cm}^{-2}\right)$. The values are more scattered because of a much larger data set than that of summer as shown by the standard deviations in Figure 2 . The spring data shows a slightly lower mean $\mathrm{OH}$ residual of $1.2 \times 10^{12} \mathrm{~cm}^{-2}$, while during winter the mean residual is below zero $\left(-1.0 \times 10^{12} \mathrm{~cm}^{-2}\right)$. The difference between MLS partial OH column and TMF total $\mathrm{OH}$ column measurements thus appears to exhibit a seasonal dependence. This is further discussed in section 4.1 with the help of GEOS-Chem estimates of the lower atmospheric $\mathrm{OH}$, where the SZA dependence of these measurements is also quantified.

\subsection{Lower Atmospheric OH Estimated With GEOS- Chem}

[22] In order to make a total column comparison between $\mathrm{OH}$ measurements from MLS and TMF, the lower atmo- spheric $\mathrm{OH}$ partial column that is not measured by MLS has to be estimated. GEOS-Chem v5-07-08 outputs for 2003 monthly mean are used to determine this partial $\mathrm{OH}$ column. As mentioned earlier, the tropospheric part is directly calculated with GEOS-Chem [Bey et al., 2001; Bloss et al., 2005], while the lower stratospheric component is calculated with the Harvard 2-D model implemented in GEOS-Chem [Schneider et al., 2000]. In this combined model, fifty five vertical layers are used to cover the entire atmosphere. The lower atmosphere below $21.5 \mathrm{hPa}$ is covered by the lowest 27-28 layers. In the following sections, "GEOS-Chem 2003" is used to refer to this combined model unless otherwise specified.

[23] Figure 3 shows the GEOS-Chem 2003 monthly mean $\mathrm{OH}$ outputs extracted for TMF area. To integrate the $\mathrm{OH}$ densities into columns, the pressure data was converted into altitudes using scale heights derived from GEOS-Chem temperature fields. The lower atmospheric $\mathrm{OH}$ was calculated by integrating model results between the surface and $21.5 \mathrm{hPa}$, for each month. However, as mentioned earlier, the $2^{\circ} \times 2.5^{\circ}$ model grid covering TMF has an average elevation that is considerably lower than TMF. The average surface pressure in this model grid is $\sim 950 \mathrm{hPa}$, much higher than the TMF surface pressure $(\sim 790 \mathrm{hPa})$. TMF falls in the fifth model layer. While the exclusion of the lowest four layers most likely introduces an underestimation of this partial $\mathrm{OH}$ column at TMF (because polluted boundary layer air that could be occasionally advected over TMF, is completed ignored), the integration from the model surface gives an upper end of the estimate. Therefore, two partial $\mathrm{OH}$ columns were calculated, integrating from the surface and the fifth model layer, as the maximum and the minimum estimates of this partial $\mathrm{OH}$ column. The minimum is typically $8-12 \%$ smaller than the maximum, depending on the time of the year (solid triangles in Figure 4). While the true partial $\mathrm{OH}$ column at TMF is unknown, it should fall in between these two estimates. The

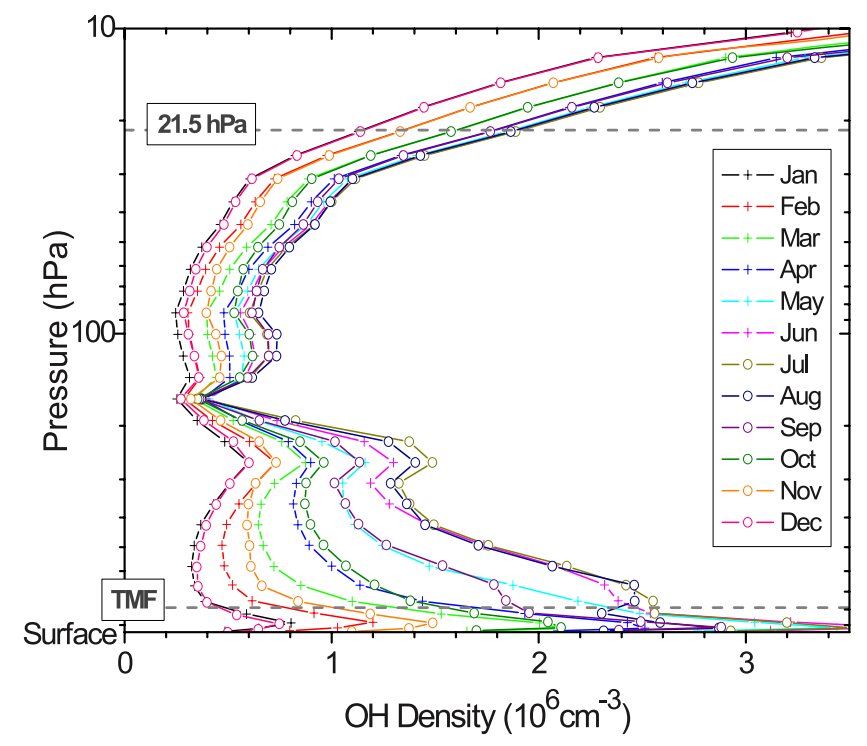

Figure 3. Monthly mean $\mathrm{OH}$ vertical profiles in 2003 calculated with GEOS-Chem. 


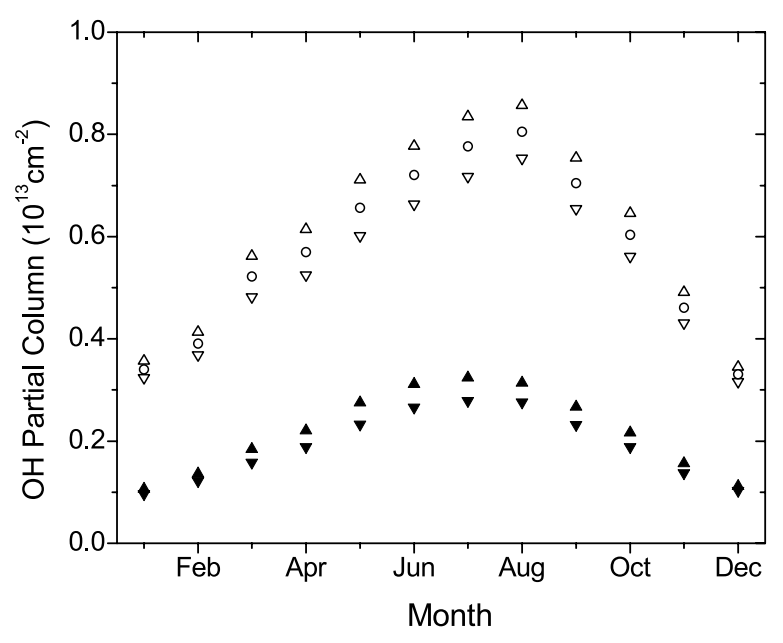

Figure 4. GEOS-Chem monthly mean $\mathrm{OH}$ partial columns before and after applying conversion factors. The solid symbols show monthly mean values over $24 \mathrm{~h}$. The open symbols show monthly mean results at satellite overpass time at TMF. The upward triangles show the maximum $\mathrm{OH}$ partial columns from model surface to $21.5 \mathrm{hPa}$. The downward triangles show the minimum $\mathrm{OH}$ partial columns from TMF to $21.5 \mathrm{hPa}$. The open circles are the mean of the maximum and minimum estimates (upward and downward open triangles) and are taken as the lower atmospheric $\mathrm{OH}$ missing from MLS measurements.

mean of the maximum and the minimum estimates is within $4-6 \%$ of the true partial $\mathrm{OH}$ column of interest.

[24] In order to convert the monthly mean $\mathrm{OH}$ data into MLS overpass time data, a conversion factor has to be estimated for each month. Given the diurnal SZA variation in each month calculated with MICA, these conversion factors were derived on the basis of observations and modeling of the variation of $\mathrm{OH}$ density with SZA in the upper troposphere and lower stratosphere [Salawitch et al., 1994; Wennberg et al., 1995]. The monthly mean lower atmospheric $\mathrm{OH}$ around the satellite overpass time was calculated by applying these factors (open triangles in Figure 4). The daily lower atmospheric $\mathrm{OH}$ was obtained through a linear interpolation of the mean of the maximum and minimum estimates. The combined total $\mathrm{OH}$ column, "MLS + GEOS-Chem," is thus obtained by adding the lower atmospheric OH from GEOS-Chem to the MLS partial $\mathrm{OH}$ column (the red points in Figure 1 (top)). In the following discussions, the term MLS + GEOS-Chem refers to the total $\mathrm{OH}$ column obtained from MLS measurements above $21.5 \mathrm{hPa}$, GEOS-Chem calculations for tropospheric $\mathrm{OH}$, and the lower stratospheric $\mathrm{OH}$ estimated with the Harvard 2-D model implemented within GEOS-Chem.

[25] To validate this semiquantitative approach of converting monthly mean to overpass time data, we compare tropospheric $\mathrm{OH}$ columns at satellite overpass time derived using the above discussed method and those calculated directly from a model version with hourly outputs. A newer version of GEOS-Chem (v7-04-10) with hourly OH outputs was employed to generate overpass time $\mathrm{OH}$ for selected months. Since March and September 2005 have the most concentrated MLS and TMF data, these months were selected. The major differences and similarities of the two model versions are listed in Table 1. The v7-04-10 model generates instantaneous $\mathrm{OH}$ profiles in the troposphere every hour. The outputs at 2100 UT are expected to be the closest to the results at MLS overpass time. The maximum tropospheric $\mathrm{OH}$ columns are calculated from the model surface in the selected $2^{\circ} \times 2.5^{\circ}$ grid to the tropopause, while the minimum tropospheric columns are calculated from the TMF elevation to the tropopause. These columns are marked as the upper and lower error bars in Figure 5. The equivalent tropospheric $\mathrm{OH}$ columns on these days derived from v5-07-08 GEOS-Chem 2003 monthly mean results are plotted together for a comparison. The dotted gray lines show a $30 \%$ uncertainty range of the estimated columns.

[26] Considering the differences between the two model versions especially the meteorology, the results in Figure 5, which mostly overlap in the $\pm 30 \%$ range, show an acceptable agreement. In particular, for September, during $88 \%$ of the calculated days the 2005 model calculations (v7-04-10) at 2100 UT fall within the $\pm 30 \%$ range of the values derived from the 2003 monthly mean outputs of v5-07-08. The fact that GEOS-Chem v7-04-10 results are generally higher than those from v5-07-08 is consistent with the previous comparisons of $\mathrm{OH}$ outputs from different versions of GEOSChem. Wu et al. [2007] reported significantly higher $\mathrm{OH}$ from models with GEOS-4 meteorology than those with GEOS-3 because of a $14 \%$ difference in radiative impacts from clouds. Hudman et al. [2007] also reported significantly higher $\mathrm{OH}$ from GEOS-4 model simulations than measurements from Intercontinental Chemical Transport Experiment-North America (INTEX-NA). Since the lower atmospheric $\mathrm{OH}$ estimated by GEOS-Chem is typically less than $12 \%$ of the total $\mathrm{OH}$ column, a $30 \%$ uncertainty in the GEOS-Chem estimation would contribute less than $3.6 \%$ to the total $\mathrm{OH}$ column. The above described derivation of the lower atmospheric $\mathrm{OH}$ partial column using GEOS-Chem 2003 monthly mean outputs should thus be adequate for the purpose of the validation of total $\mathrm{OH}$ column.

[27] As shown in Figure 1, the combined total $\mathrm{OH}$ columns from MLS + GEOS-Chem agree well with the TMF total column measurements during most days with high $\mathrm{OH}$. During winter and early spring, however, the former is often larger than the latter.

\subsection{Comparison of GEOS-Chem OH Results With Photochemical Box Model Calculations and Observations}

[28] To assess the reliability of the $\pm 30 \%$ uncertainty of the GEOS-Chem estimates of the lower atmospheric $\mathrm{OH}$, in particular between the tropopause and $21.5 \mathrm{hPa}$ where the model uncertainty is not well known, the constrained photochemical box model was employed to derive $\mathrm{OH}$ vertical profiles in the lower atmosphere to compare with GEOS-Chem results. The box model is constrained by MLS measurements of $\mathrm{H}_{2} \mathrm{O}, \mathrm{O}_{3}, \mathrm{~N}_{2} \mathrm{O}, \mathrm{CO}$, and temperature above $18 \mathrm{~km}$. From 12 to $18 \mathrm{~km}$, the model is constrained to $\mathrm{HO}_{x}$ precursors $\left(\mathrm{H}_{2} \mathrm{O}, \mathrm{O}_{3}\right.$, etc. $)$ measured by FIRS-2. This model has been previously used for validation of MLS $\mathrm{HO}_{x}$ measurements for September 2004 and 2005 [Canty et al., 2006; Pickett et al., 2006, 2008]. More details about the 

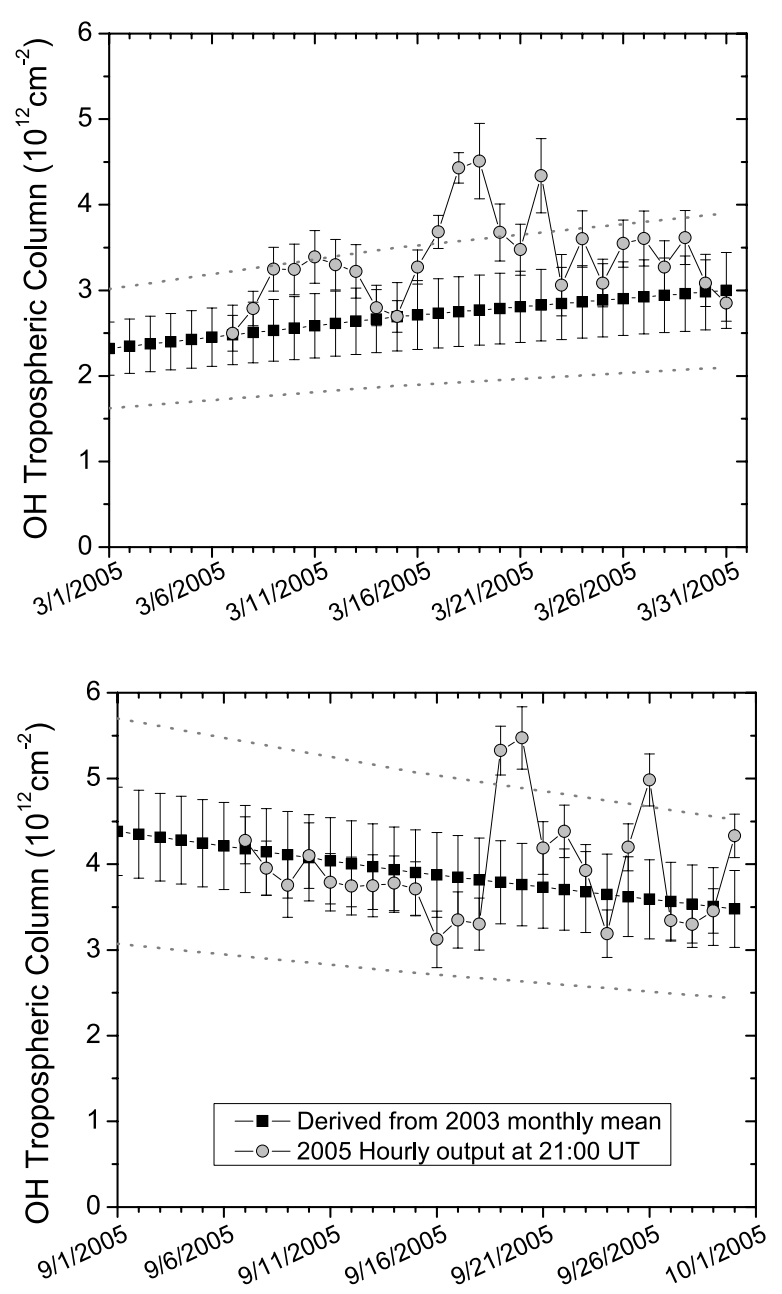

Figure 5. Comparison of the $\mathrm{OH}$ tropospheric columns at MLS overpass time from two versions of GEOS-Chem. Black squares indicate the estimates derived from 2003 monthly mean results (v5-07-08). Gray circles show v7-0410 outputs at 2100 UT. The upper and lower error bars show the maximum and minimum estimates of the tropospheric $\mathrm{OH}$ column calculated from the model surface and TMF elevation, respectively. The symbols show the mean of the maxima and the minima. The $\pm 30 \%$ uncertainty range of the derived tropospheric columns is marked with the gray dotted lines.

model and the included chemical kinetics are described by Canty et al. [2006].

[29] Figure 6 shows the comparison of GOES-Chem 2003 and box model results for various seasons. The daily mean results from the box model on 15 March, 15 June, 23 September, and 23 December 2004 are compared with the corresponding GEOS-Chem 2003 monthly mean results. The results shown by the black lines in Figure 6 are a combination of the box model calculations and observations. The box model calculates $\mathrm{OH}$ profiles above $12 \mathrm{~km}$ altitude. The $\mathrm{OH}$ levels at $8-12 \mathrm{~km}$ are empirical estimates on the basis of the SZA variation of $\mathrm{OH}$ and observations from an instrument on board the NASA ER-2 aircraft in the free troposphere during the STRAT (Stratospheric Tracers of Atmospheric Transport) mission [Wennberg et al., 1998]. Observations from Meteorological Observatory Hohenpeissenberg in Germany [Rohrer and Berresheim, 2006] and INTEX-NA (see http://www.espo.nasa.gov/intex-na/data.html for details) are also used to derive the boundary layer $\mathrm{OH}$ shown in Figure 6. The agreement between GEOS-Chem 2003 and the box model results is good between $100-$ $20 \mathrm{hPa}$. At $100-300 \mathrm{hPa}$ where $\mathrm{OH}$ has the lowest density, the box model/observation results are $10-50 \%$ lower than GEOS-Chem 20003 results, while the agreements in the boundary layer are generally good except for the winter scenario. The integrated lower atmospheric $\mathrm{OH}$ partial columns from the box model/observations agree with GEOS-Chem 2003 results within 30\%, justifying the uncertainty we have associated with the GEOS-Chem 2003 estimates of the lower atmospheric $\mathrm{OH}$.

[30] MLS measurements in the lower stratosphere are also shown in Figure 6. As mentioned earlier, the precision of MLS OH measurements below $21.5 \mathrm{hPa}$ is poor. Nevertheless, the zonal mean $\mathrm{OH}$ data can be used to compare with the model calculations in the lower stratosphere, in particular below $21.5 \mathrm{hPa}$. For an easy comparison, the MLS data were converted into daily mean data by applying the conversion factor described in section 3.2. Both model results agree with MLS within the $1 \sigma$ measurement precision (shown by error bars), except for 15 June 2004 during which the MLS measurements are higher than both model results.

[31] On 23 September 2004, measurements in the lower stratosphere from $\mathrm{BOH}$ and FIRS-2 close to the MLS overpass time are also compared with the model calculations (Figure 6). Details of the balloon flight on this day were given by Pickett et al. [2006]. These observations agree with both model calculations except for one point out of BOH data at $\sim 30 \mathrm{hPa}$.

[32] Figure 7 provides a further comparison for $100-$ $200 \mathrm{hPa}$. Measurements from STRAT [Wennberg et al., 1998] at comparable latitudes $\left(35.9-37.3^{\circ} \mathrm{N}\right.$ for flight $960202,37.9-40.5^{\circ} \mathrm{N}$ for flight $951031,21.6-22.1^{\circ} \mathrm{N}$ for flight 951107) and longitudes $\left(121.4-122.3^{\circ} \mathrm{W}\right.$ for flight $960202,122.2-122.9^{\circ} \mathrm{W}$ for flight $951031,159.4-$ $160.6^{\circ} \mathrm{W}$ for flight 951107 ) are converted into daily mean $\mathrm{OH}$ and compared with GEOS-Chem 2003 monthly mean results. The STRAT observations agree well with the model data, further justifying the $\pm 30 \%$ uncertainty associated with estimates of the lower atmospheric OH from GEOS-Chem 2003.

\section{Discussion}

\subsection{Seasonal and SZA Variations of the Total $\mathrm{OH}$ Columns}

[33] Since the comparisons in Figure 1 and Figure 2 show a different seasonal variation in the measurements from MLS and TMF, it is necessary to investigate the seasonal and SZA dependence of the observations. Figure 8 shows the seasonal histograms of the total OH columns from MLS + GEOS-Chem and TMF. The distribution of these two groups of total $\mathrm{OH}$ columns shows a close agreement in summer though the data set is small. During spring and fall, the data sets are reasonably large. Their distributions generally agree, with TMF results being slightly lower than 

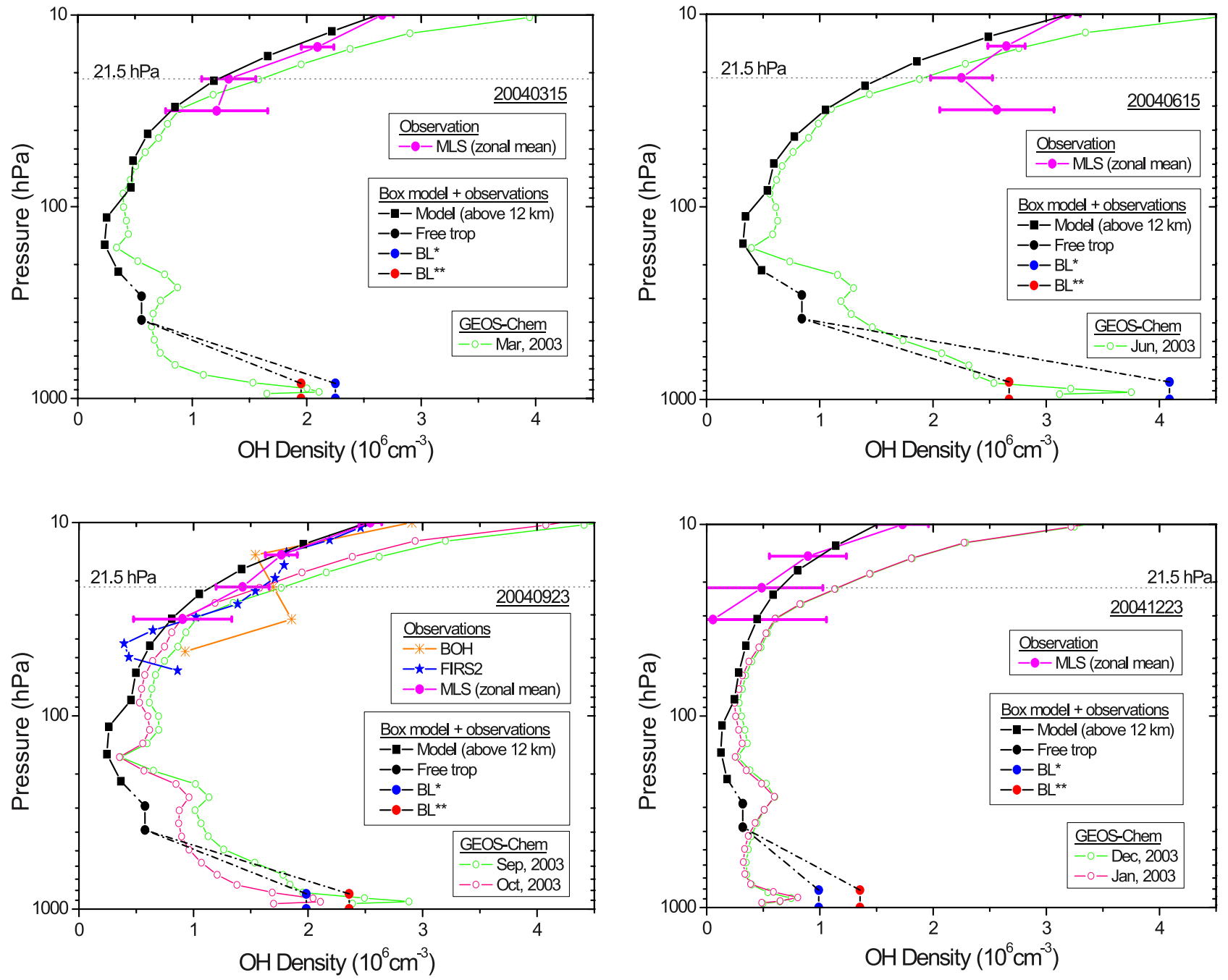

Figure 6. Comparison between field observations and model calculations of the $\mathrm{OH}$ distribution in the troposphere and lower stratosphere on a selected day for each season. The $\mathrm{OH}$ vertical profiles denoted by the black, blue, and red symbols are a combination of results from the photochemical box model and observations. The model calculates daily mean $\mathrm{OH}$ vertical profiles above $12 \mathrm{~km}$ over TMF. The $\mathrm{OH}$ from $12 \mathrm{~km}$ down to $8 \mathrm{~km}$ is based on the STRAT observations in the free troposphere [Wennberg et al., 1998]. The boundary layer $\mathrm{OH}$ is derived from two sets of observations (BL* data from Rohrer and Berresheim [2006] and BL** data from INTEX-NA). GEOS-Chem 2003 monthly mean OH profiles during the comparable months are shown. MLS measurements in the lower stratosphere and BOH and FIRS-2 measurements close to the MLS overpass time are converted into daily mean $\mathrm{OH}$ for an easy comparison.

MLS + GEOS-Chem. During winter, however, there is a significant difference between these two data sets.

[34] The histograms for various SZA bins (Figure 9) help to further investigate the difference in seasonal variations of TMF and MLS + GEOS-Chem results. The data with SZAs of $\left[20^{\circ}, 30^{\circ}\right]$ correspond to the summertime data in Figure 8. The SZA bin of $\left[30^{\circ}, 40^{\circ}\right]$ shows a good agreement between the total $\mathrm{OH}$ columns. When the SZA is above $40^{\circ}$, a small discrepancy is observed. At SZAs of $\left[50^{\circ}, 60^{\circ}\right]$, the combined total $\mathrm{OH}$ column from MLS + GEOS-Chem is considerably larger than TMF measurements.

[35] The results of the two-group-independent $T$ test [Press et al., 1992] are also summarized in Table 2, which provides quantitative insights to the seasonal comparison. The mean of the TMF total $\mathrm{OH}$ columns decreases from $6.89 \times 10^{13} \mathrm{~cm}^{-2}$ at the smallest SZAs to $4.76 \times 10^{13} \mathrm{~cm}^{-2}$ at the largest SZAs, while the difference of means (DOM) increases significantly from $1.02 \times 10^{12}$ to $4.99 \times 10^{12} \mathrm{~cm}^{-2}$. The data set at SZA of $\left[20^{\circ}, 30^{\circ}\right]$ is likely too small to make a meaningful comparison. The SZA bin of $\left[30^{\circ}, 40^{\circ}\right]$ has a large enough data set and shows a good agreement between TMF and MLS + GEOS-Chem. The mean of the MLS + GEOS-Chem total columns in this bin is only 3\% larger than the mean of TMF total columns. At the largest SZA bin $\left[50^{\circ}, 60^{\circ}\right]$, the former is shown to be $10.5 \%$ larger than the latter. The $T$ value also increases from 1.12 to 5.86 with the 


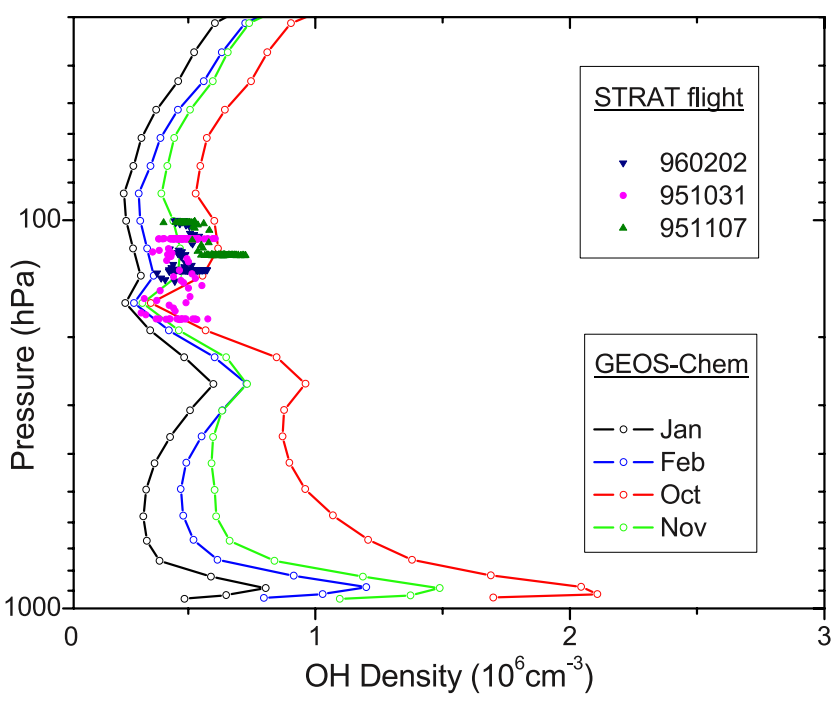

Figure 7. Comparison of $\mathrm{OH}$ distribution from GEOSChem 2003 monthly mean outputs and STRAT observations in 1995-1996. The STRAT OH densities around the MLS overpass time (1300-1330 LST (local standard time)) on three selected days were converted into daily mean to compare with the GEOS-Chem monthly mean $\mathrm{OH}$ vertical profiles.

increase of SZA from $\left[20^{\circ}, 30^{\circ}\right]$ to $\left[50^{\circ}, 60^{\circ}\right]$. At a $95 \%$ confidence level, the data at SZAs above $40^{\circ}$ show statistically significant differences, especially at $50^{\circ}$ and above.

[36] At large SZAs in winter, the viewing angle of the FTUVS instrument is toward the south. The geographic deviation of the sampled air mass with respect to the location of the instrument increases with increasing SZA. For $45 \mathrm{~km}$ and $75 \mathrm{~km}$ altitudes where $\mathrm{OH}$ density often peaks, the horizontal deviation for a SZA of $60^{\circ}$ is about $78 \mathrm{~km}$ and $130 \mathrm{~km}$. While this change in instrument viewing angles may be a source of the difference in the observations, it is rather small, especially considering that the latitude grid of MLS results covers 10 degrees.

[37] Figure 10a shows the decay of the total $\mathrm{OH}$ columns with the increase of SZA for the total $\mathrm{OH}$ columns from MLS + GEOS-Chem and TMF during the near 3 year period shown in Figure 1. The TMF error bars are the $1 \sigma$ spectral fit uncertainties from the data analysis. The error bars for MLS + GEOS-Chem data are the RSS (root sum square) of MLS spectral retrieval precision $(1 \sigma)$ and an assumed $30 \%$ uncertainty in the estimate of the lower atmospheric OH using GEOS-Chem 2003. The SZA variation of MLS results appears to be slightly weaker than TMF measurements. Since MLS and FTUVS measure $\mathrm{OH}$ at the microwave and the UV region, respectively, the uncertainties in the relative absorption cross sections from microwave to UV could contribute to the different seasonal variations in these measurements. While the cross sections for microwave $\mathrm{OH}$ lines are quite precise, some instrumental uncertainties have the effect of changing the effective cross sections. An overestimation of the cross sections in the microwave region could result in an underestimation in retrieved MLS OH columns for all seasons. Conversely, an underestimation of the cross sections in UV could lead to an overestimation in TMF results. The potential error due to this effect decreases as the $\mathrm{OH}$ abundance decreases at larger SZAs. One or both of the above mentioned cross section uncertainties could be responsible for a lightly weaker overall seasonal/SZA variation in MLS results than TMF results.
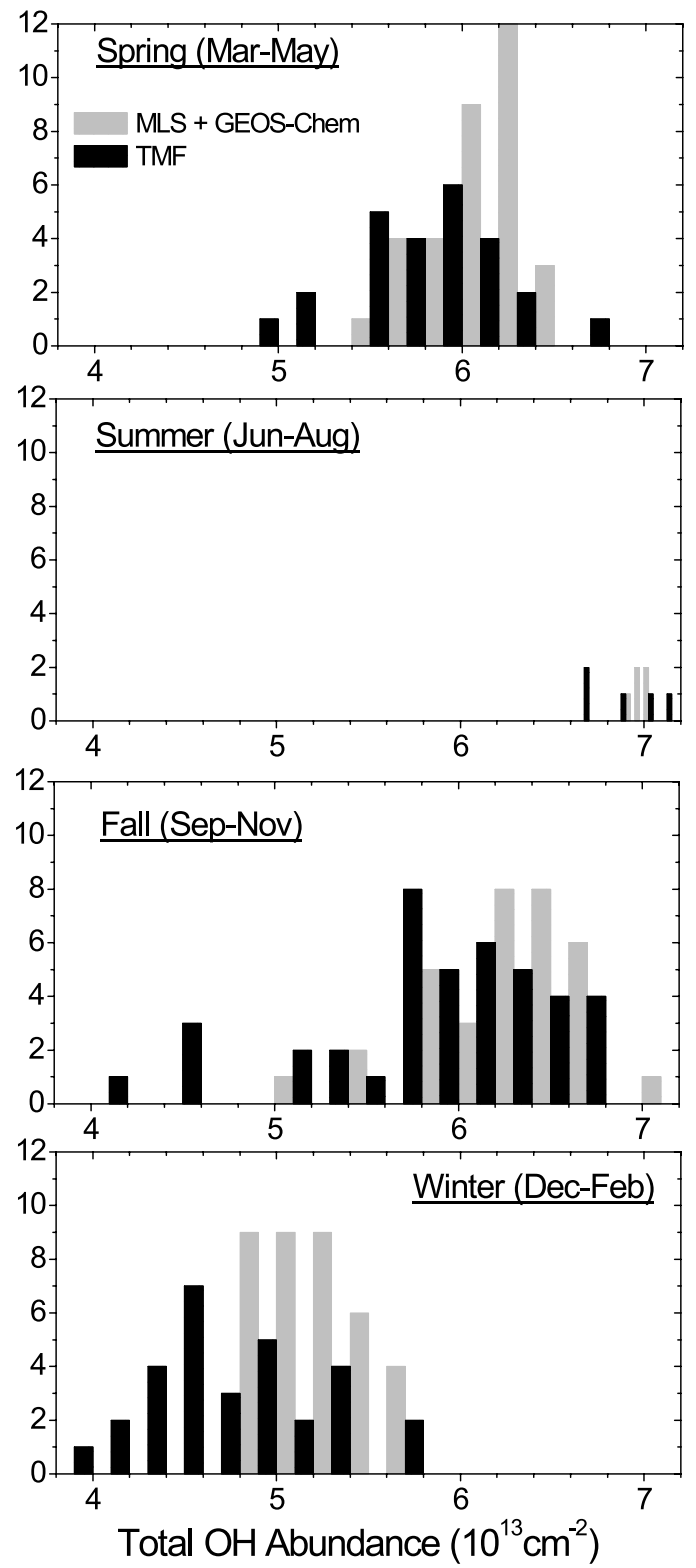

Figure 8. Seasonal histograms of total $\mathrm{OH}$ columns at satellite overpass time from TMF measurements and the sum of MLS and GEOS-Chem partial OH columns. Because of the small data set during summer time, the bin in the histogram (indicated by the width of the vertical bars) is $0.5 \times 10^{12} \mathrm{~cm}^{-2}$, while the bin for the other seasons is $2 \times 10^{12} \mathrm{~cm}^{-2}$. The agreement is good in summer. The fall and winter agreements are fairly good, while differences are seen in winter. 


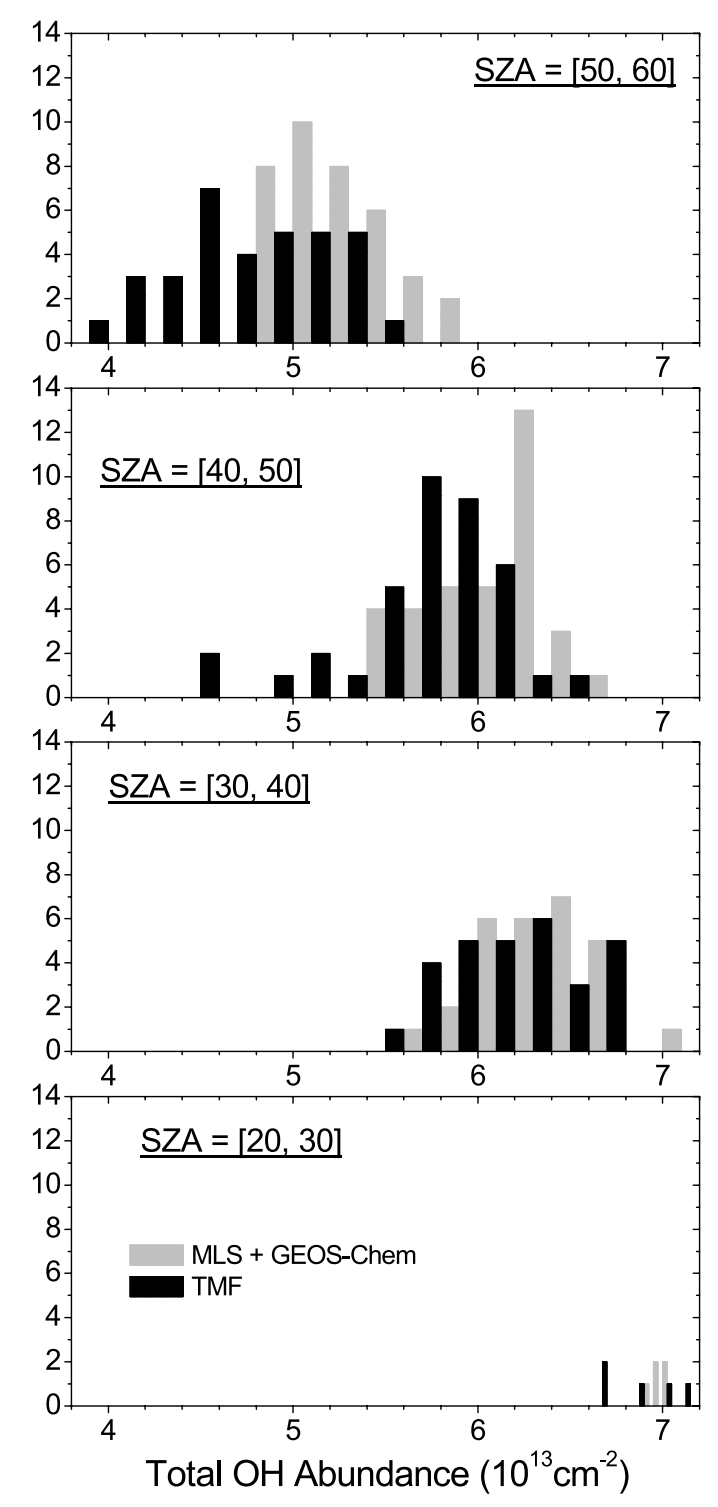

Figure 9. Histograms of total $\mathrm{OH}$ columns from TMF measurements and the sum of MLS and GEOS-Chem partial $\mathrm{OH}$ columns for different SZA ranges. Because of the small data set at $[20,30]$ SZAs, the bin in the histogram (the width of the vertical bars) is $0.5 \times 10^{12} \mathrm{~cm}^{-2}$, while the bin for the other SZAs is $2 \times 10^{12} \mathrm{~cm}^{-2}$. Data with SZA below $40^{\circ}$ show a good agreement between MLS + GEOSChem and TMF measurements. Above $40^{\circ}$ SZA differences are observed, especially for the SZA bin of $[50,60]$. The corresponding two-sample-independent $T$ test results for each SZA bin, including $T$ values, the degree of freedom, and the difference of mean, are listed in Table 2.

\subsection{Linear Correlation of the Total $\mathrm{OH}$ Columns}

[38] Figure 11 shows the linear correlation of the combined total OH columns from MLS + GEOS-Chem versus the measured total $\mathrm{OH}$ columns from TMF during September 2004 through April 2007. The data points are color coded. Black indicates that TMF measurements occurred on the same day as MLS measurements. Red means that the measurements were one day apart. It should also be noted that some TMF data points are used more than once in this correlation analysis. For example, TMF data on 24 September 2004 are compared with the MLS data on 24 September 2004 as a same day data point and also compared with MLS data on 25 September 2004 as a next day data point. The horizontal error bars are the TMF spectral fit uncertainties; the vertical error bars are the RSS combination of MLS precision and the $30 \%$ uncertainty in the lower atmospheric $\mathrm{OH}$ (see section 4.1). A number of different least squares linear regression methods have been applied to the data in Figure 11 to obtain a comprehensive view of the correlation and to quantify the accuracy of the MLS + GEOS-Chem $\mathrm{OH}$ column relative to the TMF $\mathrm{OH}$ column. The results are listed in Table 3 and described below.

\subsubsection{Standard Linear Regression}

[39] Without considering the errors, the linear fit through zero generates a slope of 1.065 , which indicates good agreement, within $6.5 \%$, between these two groups of total $\mathrm{OH}$ columns. When the slope is constrained to unity, the linear fit results in an intercept of $0.397 \times 10^{13} \mathrm{~cm}^{-2}$. Considering the range of the TMF total $\mathrm{OH}$ columns in this study $\left(\sim 3.8 \times 10^{13}-7.1 \times 10^{13} \mathrm{~cm}^{-2}\right)$, this intercept implies an offset of about $5.6-10 \%$, depending on the time of the year. The correlation coefficient $(R)$ is about 0.85 for all cases. A standard linear fit without constraints, however, gives a much smaller slope $(0.673)$ and a much larger intercept $\left(2.203 \times 10^{13} \mathrm{~cm}^{-2}\right)$. A closer look at the correlation in Figure 11 suggests good agreement at high $\mathrm{OH}$ but a difference at low $\mathrm{OH}$ conditions (also shown in Figure 1), which significantly influences the linear fit results. The standard fit with $y$ error bars weighted show very similar results. It has to be noted that all the above mentioned least squares linear regression calculations assume that data in the abscissa, TMF $\mathrm{OH}$ column, is the reference with no error. It is therefore worth investigating the linear regression results that consider deviations and errors in TMF OH data as well as the MLS data.

4.2.2. Orthogonal Least Squares Linear Fit With Both $x$ and $y$ Errors Weighted

[40] An orthogonal least square regression takes into account the deviation of the measured points in both $x$ and $y$ directions from the fitted line. Instead of minimizing the sum of the squared vertical distance from the measured data to the fitted line as in a standard linear fit, the orthogonal regression (or "total" least squares regression) finds the minimum of the sum of the squared orthogonal distance between the measurements $(x, y)$ and the predictions $(X, Y)$. The intercept $a$ and slope $b$ of the orthogonal linear fit with $x$ and $y$ errors $\left(\sigma_{x}\right.$ and $\sigma_{y}$ ) weighted is obtained by minimizing $\chi^{2}$,

$$
\chi^{2}=\sum_{i}\left[\frac{\left(X_{i}-x_{i}\right)^{2}}{\sigma_{x i}^{2}}+\frac{\left(Y_{i}-y_{i}\right)^{2}}{\sigma_{y i}^{2}}\right],
$$

which is further rewritten as equations (2) and (3) [Press et al., 1992; Reed, 1989, 1992; York, 1966]

$$
\chi^{2}=\sum_{i} \frac{\left(y_{i}-a-b x_{i}\right)^{2}}{\sigma_{y i}^{2}+b^{2} \sigma_{x i}^{2}}
$$


Table 2. Two-Sample-Independent $T$ Test Results for the Total OH Columns From TMF and MLS + GEOSChem for Different SZAs ${ }^{\text {a }}$

\begin{tabular}{lcccc}
\hline \multicolumn{1}{c}{ SZA } & {$\left[20^{\circ}, 30^{\circ}\right]$} & {$\left[30^{\circ}, 40^{\circ}\right]$} & {$\left[40^{\circ}, 50^{\circ}\right]$} & {$\left[50^{\circ}, 60^{\circ}\right]$} \\
\hline Mean $\left(10^{13} \mathrm{~cm}^{-2}\right)$ & & & & \\
MLS + GEOS-Chem & 6.99 & 6.35 & 6.09 & 5.26 \\
TMF & 6.89 & 6.17 & 5.70 & 4.76 \\
$T$ value & 1.12 & 2.09 & 4.36 & 5.86 \\
Degree of freedom & 8 & 55 & 71 & 69 \\
Difference of mean $\left(10^{13} \mathrm{~cm}^{-2}\right)$ & 0.102 & 0.184 & 0.384 & 0.499 \\
\hline
\end{tabular}

${ }^{\text {a }}$ See Figure 9 for the corresponding histogram plots.

$$
a=\frac{\sum_{i} \frac{y_{i}-b x_{i}}{\sigma_{y i}^{2}+b^{2} \sigma_{x i}^{2}}}{\sum_{i} \frac{1}{\sigma_{y i}^{2}+b^{2} \sigma_{x i}^{2}}}
$$

The results of this orthogonal linear fit are shown in Table 3 and Figure 11 (the green line). The slope is found to be 0.835 with an intercept of $1.308 \times 10^{13} \mathrm{~cm}^{-2}$. This confirms the trend shown by the standard linear regression, although the orthogonal fit with both error bars is considerably closer to the $1: 1$ line.

\subsubsection{Contour Mapping of the Orthogonal Reduced Chi Squared}

[41] The distribution of the reduced Chi squared, $\chi_{\text {reduced, }}^{2}$ which is the $\chi^{2}$ in equations (1) and (2) divided by the degree of freedom $(n-2)$, provides a useful approach to investigate the deviations of the intercept from a value of 0 and of the slope from a value of 1 . Figure 12 illustrates the contour mapping of $\chi_{\text {reduced }}^{2}$ as a function of the intercept and the slope. Note that the shape of the contours is far from circular. The long and narrow contours are diagonal, going from slopes near unity and intercepts close to zero (shown by the red solid lines) down to smaller slopes and larger intercepts. The intersection of the two green lines in Figure 12 represents the best orthogonal fit, with a minimum $\chi_{\text {reduced }}^{2}$ of 1.150 (scenario 1 in Table 4).

[42] While the 1-to-1 line clearly deviates from the best fit, the minimum values of $\chi_{\text {reduced }}^{2}$ at a unity slope and at a zero intercept, marked with red crosses in Figure 12, are not significantly larger than the best fit. The solid curves in Figure 13 show the distributions of $\chi_{\text {reduced }}^{2}$ at a constrained slope and a constrained intercept, respectively. The orthogonal fit with a zero intercept results in a slope of 1.073 with a $\chi_{\text {reduced }}^{2}$ of 1.321 (scenario 2 in Table 4), while the fit with a unity slope yields an intercept of $0.414 \times 10^{13} \mathrm{~cm}^{-2}$ with a $\chi_{\text {reduced }}^{2}$ of 1.239 (scenario 3 ). An "optimal" solution is achieved by constraining the intercept to $0.2 \times 10^{13} \mathrm{~cm}^{-2}$, about half of the value found in scenario 3 . The resulting optimal slope is 1.037 with the $\chi_{\text {reduced }}^{2}$ being 1.279 (scenario 4).

[43] Considering the small change of $\chi_{\text {reduced }}^{2}$ in the various fits (also shown by the shape of the contour mapping in Figure 12), there is no single approach that stands out as the "best fit." The contour mapping of $\chi_{\text {reduced }}^{2}$ and the list of fits in Table 4 thus provides a complete view of the correlation between these measurements and possible ranges of the slope and the intercept. It is reasonable to draw conclusions on the basis of the mean solution of the above mentioned scenarios. When the intercept is constrained at
$0.574 \times 10^{13} \mathrm{~cm}^{-2}$, the mean value of scenarios $1-3$, the "mean" slope is found to be 0.969 with a $\chi_{\text {reduced }}^{2}$ as small as 1.212 (scenario 5). The differences suggested by the optimal fit and the mean fit are all well below the systematic uncertainties in both measurement techniques.
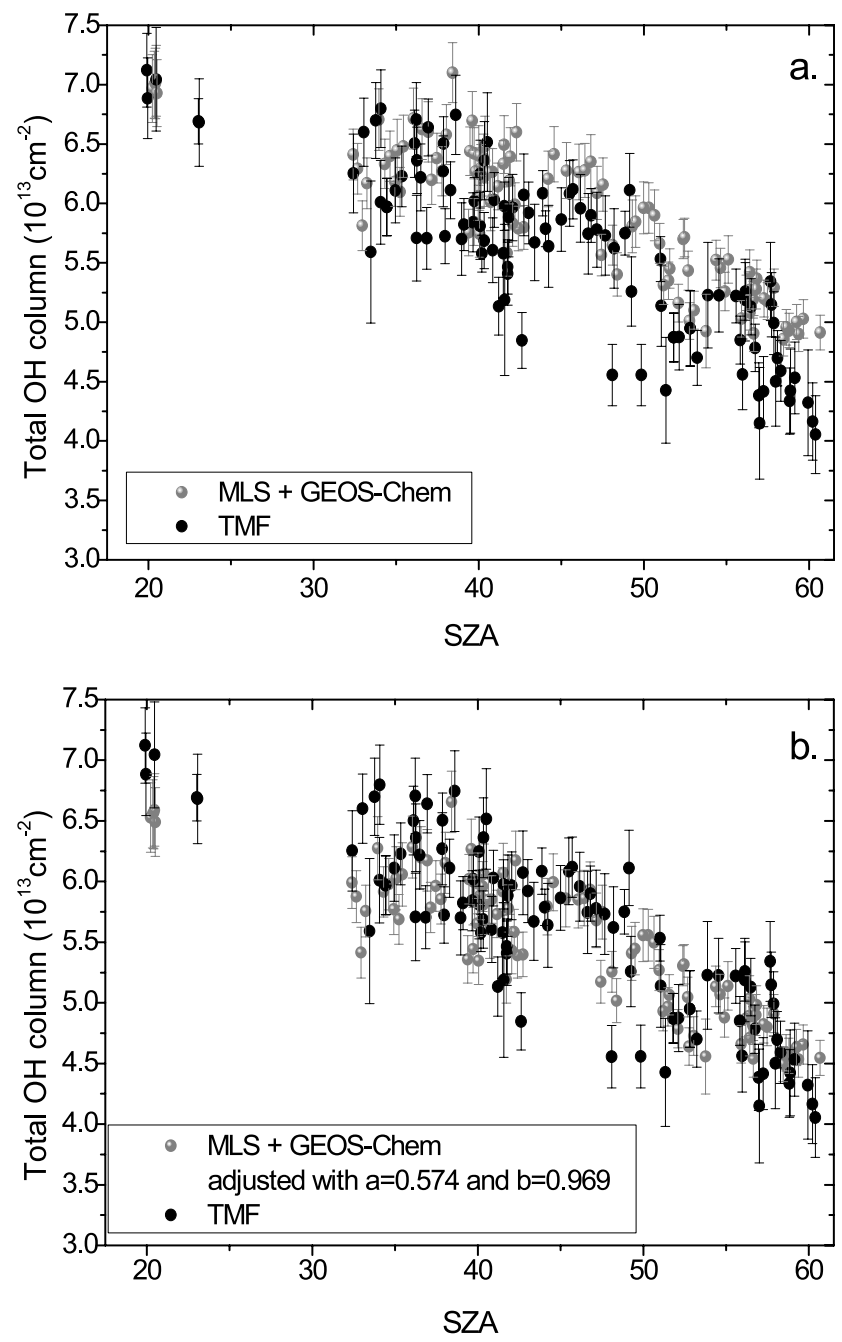

Figure 10. Comparison of SZA variations of the total $\mathrm{OH}$ columns from MLS + GEOS-Chem and TMF. (a) SZA variations of the original data. (b) The total $\mathrm{OH}$ columns from MLS + GEOS-Chem are adjusted with the mean intercept and slope from the orthogonal linear fit. The error bars are $1 \sigma$ precision from the spectral retrieval. For MLS + GEOS-Chem total $\mathrm{OH}$ columns, the error bars also include an assumed $30 \%$ uncertainty of the estimation of the $\mathrm{OH}$ partial column below $21.5 \mathrm{hPa}$. 


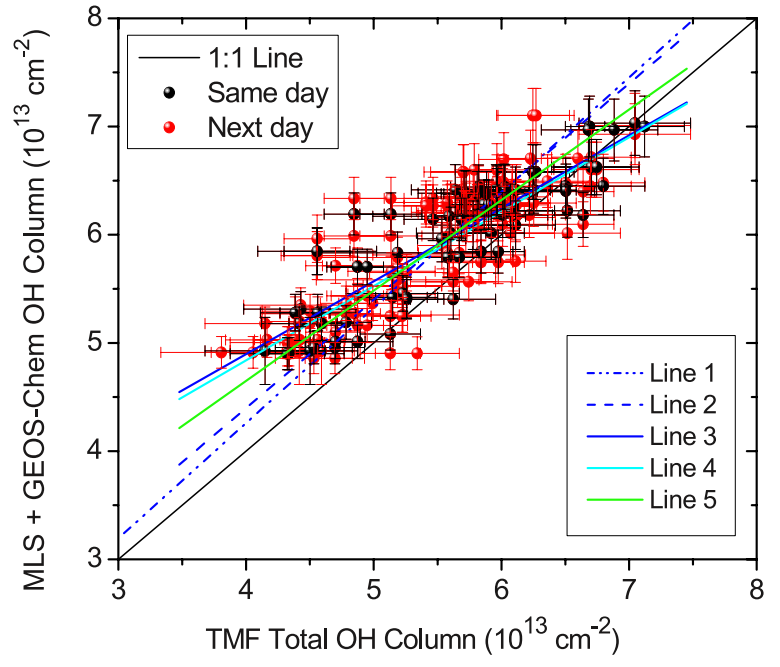

Figure 11. Correlation of $\mathrm{OH}$ total columns from MLS + GEOS-Chem versus OH total columns from TMF measurements. Data during days when MLS and TMF measurements were both available are indicated with black ("same day" points). When MLS and TMF measurements are 1 day apart, the data are marked as "next day" points in red. See Figure 10 caption for the description of the error bars. The legends of the fitted lines and the corresponding slopes and intercepts are shown in Table 3.

[44] As discussed in section 4.1, the MLS and TMF measurements appear to have slightly different seasonal or SZA variations (Figure 10a). By applying the mean slope and intercept, the total OH column data from MLS + GEOS-Chem are adjusted in Figure 10b. The adjusted data and the measurements from TMF overlap very well within the precision error bars from both data sets, which further confirms that the mean slope and intercept provide a reasonable description of the difference between the two data sets.

[45] Another technique different from the SZA method described in section 3.1 was also used to select the comparable TMF data at MLS overpass time for this investigation. Instead of selecting two data points (on most days) measured during time spans covering the MLS SZA, this alternative method applies a second-order polynomial (parabolic function) fit to the diurnal variation of TMF $\mathrm{OH}$ data during each day. The TMF OH column result at the MLS overpass time was derived from the fitted curve. This "parabolic selection" results in linear correlations between MLS + GEOS-Chem and TMF total OH columns that are very similar to, but not better than, those shown in Figures 11 and 12.

\subsection{Possible Causes of the Differences}

[46] The difference between the total $\mathrm{OH}$ columns from MLS + GEOS-Chem and TMF measurements could have a number of possible origins, including the model estimates of the lower atmospheric $\mathrm{OH}$, the instrument viewing angles, different spectral regions of MLS and TMF measurements, and systematic errors associated with the instruments and the retrieval algorithms. None of these is found to be a dominant cause of the above discussed differences. Each is discussed below.

[47] One potential error source arises from the model estimate of $\mathrm{OH}$ in the lower atmosphere. While the uncertainty in the lower atmospheric $\mathrm{OH}$ may contribute to the differences in both the slope error and the intercept error, the impact should be less than a few percent since the $\mathrm{OH}$ abundance below $21.5 \mathrm{hPa}$ is on the order of $10 \%$ and in most cases less than $12 \%$ of the total $\mathrm{OH}$ abundance. An assumed $30 \%$ uncertainty has already been factored into the $1 \sigma$ precision of the combined total column of MLS + GEOS-Chem (the error bars in Figure 11). As for the systematic measurement errors, as mentioned earlier, the FTUVS viewing angle at large SZAs and the different relative absorption cross sections from UV to microwave could contribute to the difference in seasonal/SZA variations in total $\mathrm{OH}$ columns from TMF and MLS + GEOSChem. Considering the fact that the size of the latitude grid of MLS results is larger than the viewing angle range from TMF, the impact of the view angle factor will be small. Instrument offsets are also unlikely to contribute significantly to the observed differences. The MLS measures $\mathrm{OH}$ at both daytime and nighttime. The nighttime data are used to correct the daytime measurements, which minimizes the systematic offset [Pickett et al., 2008]. While the FTUVS measures $\mathrm{OH}$ only during the day, the measurement technique is straightforward and does not involve any major source of offset. Since the synthetic Doppler OH line shape used in the TMF spectral fit is modeled for $250 \mathrm{~K}$, the average $\mathrm{OH}$ column temperature based on a $\mathrm{OH}$ density weighted model of the atmospheric temperature profile [Cageao et al., 2001], the pressure broadening in the lower atmosphere could in principle influence the line shape and contribute errors to the retrieval results. However, the $\mathrm{OH}$ abundance in the lower atmosphere where pressure broadening is significant is small. Thus the potential impact is a few percent. Temperature profiles at TMF have been measured by lidar since 1989 [Leblanc and McDermid, 2000; T. Leblanc, unpublished data, 2005], which provides

Table 3. Results of Different Linear Correlations Between the Total OH Columns From MLS + GEOS-Chem and $\mathrm{TMF}^{\mathrm{a}}$

\begin{tabular}{lccr}
\hline \multicolumn{1}{c}{ Type of Linear Fit } & Slope & Intercept $\left(10^{13} \mathrm{~cm}^{-2}\right)$ & $R$ \\
\hline No error weighted & & & \\
Fit through 0 (Line 1) & $1.065 \pm 0.005$ & 0 & 0.854 \\
Fit with unity slope (Line 2) & 1 & $0.397 \pm 0.027$ & 0.854 \\
Standard fit (Line 3) & $0.673 \pm 0.029$ & $2.203 \pm 0.161$ & 0.854 \\
Standard fit with $y$ errors weighted (Line 4) & $0.686 \pm 0.019$ & $2.095 \pm 0.101$ & 0.850 \\
Orthogonal fit with $x$ and $y$ error $s$ weighted (Line 5) & $0.835 \pm 0.185$ & $1.308 \pm 0.003$ & 0.855 \\
\hline a'See Figure 11. & & &
\end{tabular}




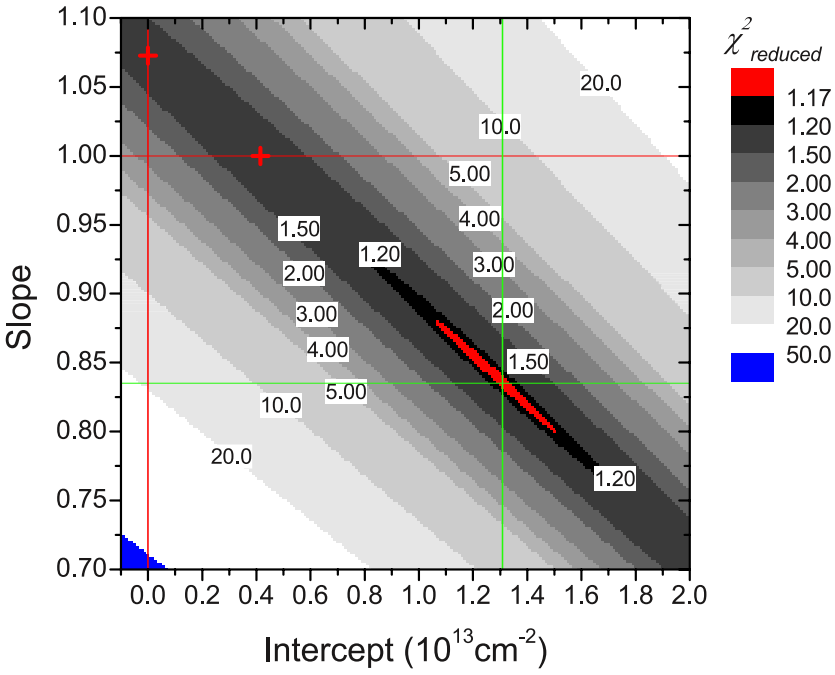

Figure 12. Contour mapping of the orthogonal Chi square $\chi^{2}$ calculations for the linear correlation of total $\mathrm{OH}$ abundances in Figure 11 (MLS + GEOS-Chem versus TMF measurements). The calculation is given in equation (1). The red horizontal and vertical lines show the distribution of reduced $\chi^{2}$ for linear regressions with fixed slope (unity) and fixed intercept (zero), respectively, with the minimum $\chi^{2}$ being marked by the red crosses. The intersection of the green lines denotes the minimum $\chi^{2}$ of the orthogonal linear fit with no constraint.

sufficient information for estimating the average $\mathrm{OH}$ column temperature. It is very unlikely for the $\mathrm{OH}$ column temperature to vary more than $30 \mathrm{~K}$. Temperature sensitivity studies indicated that the retrieved column abundance varied only $\pm 7 \%$ for a temperature change as large as $\pm 30 \mathrm{~K}$ [Cageao et al., 2001].

\subsection{MLS and FTUVS Comparison in the Context of Previous Ground-Based $\mathrm{OH}$ Column Measurements}

[48] $\mathrm{OH}$ is a very reactive, short-lived species with a small optical depth in the direct solar beam. It has therefore been difficult to make reliable, long-term column abundance measurements from the ground. The previously reported $\mathrm{OH}$ column measurements from different midlatitude observation sites have shown differences as large as a factor of two [Iwagami et al., 1998; Mills et al., 2002]. Besides TMF, long-term $\mathrm{OH}$ column measurements have been made at a number of different midlatitude sites including the NOAA Fritz Peak Observatory, Colorado
(FPO) $\left(40^{\circ} \mathrm{N}, 105^{\circ} \mathrm{W}\right)$ since 1977 [Burnett and Burnett, 1996], Tokyo, Japan $\left(36^{\circ} \mathrm{N}, 140^{\circ} \mathrm{E}\right)$ during $1992-1995$ [Iwagami et al., 1998], and Socorro, New Mexico (NMT) $\left(34^{\circ} \mathrm{N}, 107^{\circ} \mathrm{W}\right)$ since 1996 [Minschwaner et al., 2003]. Although large diurnal and seasonal variations complicate direct comparisons of data from different sites, the measurements suggest differences in total column $\mathrm{OH}$ abundances, some of which may be attributed to geographic or temporal effects. Since different types of instruments and different measurement approaches are involved, some differences could be of instrumental origin. The origin(s) of the systematic differences in their comparisons with atmospheric model calculations remain unclear [Iwagami et al., 1998].

[49] The present work is the first long-term comparison between $\mathrm{OH}$ measurements from space- and ground-based instruments. The overall agreement between MLS and TMF $\mathrm{OH}$ observations, with the help of model calculations, is remarkably good. Considering the differences in observing platforms (space versus ground) and measurement techniques (microwave thermal emission versus ultraviolet solar absorption), the observed data correlation (mean slope of 0.969 with a correlation coefficient of 0.85 ) is exceptional. These results confirm that ground-based remote sensing measurements can contribute significantly to the present and future validation of MLS data products, especially $\mathrm{OH}$.

\section{Conclusions}

[50] Total column $\mathrm{OH}$ based on measurements by the MLS instrument ( $\sim 90 \%$ of the total) and a combined model of GEOS-Chem and Harvard 2-D model $(\sim 10 \%$ of the total) agree with total column $\mathrm{OH}$ measured by the TMF FTUVS instrument to within $3.1 \%$ during a near 3 year period. This is the first seasonal and interannual comparison of $\mathrm{OH}$ column measurements from an established groundbased instrument and values inferred from space-based measurements.

[51] The agreement between the two total $\mathrm{OH}$ columns is the best for low SZAs (high $\mathrm{OH}$ ). Differences present at large SZAs, especially when SZA exceeds $50^{\circ}$ (low $\mathrm{OH}$, typically during winter). The disagreements at high SZAs (low $\mathrm{OH}$ ) suggest a slightly weaker seasonal variation of column $\mathrm{OH}$ inferred from MLS measurements than that of total column $\mathrm{OH}$ measured by the TMF FTUVS.

[52] While the instrument-based cause of this discrepancy has not been identified, it is suggested that possible causes include, but are not limited to, the difference in the relative absorption cross section from UV to microwave, the estimation of the lower atmospheric $\mathrm{OH}$, and the different instrument viewing angles at large SZAs during winter time.

Table 4. Results of the Orthogonal Linear Fit With Different Constraints of the Slope and the Intercept ${ }^{\mathrm{a}}$

\begin{tabular}{lccc}
\hline Constraints Applied for the Orthogonal Linear Fit & Slope & Intercept $\left(10^{13} \mathrm{~cm}^{-2}\right)$ & $\chi_{\text {reduced }}^{2}$ \\
\hline No constraint (scenario 1) & $0.835 \pm 0.185$ & $1.308 \pm 0.003$ & 1.150 \\
Fixed intercept (scenario 2) & $1.073 \pm 0.042$ & 0 & 1.321 \\
Fixed slope (scenario 3) & 1 & $0.414 \pm 0.001$ & 1.239 \\
Optimal intercept (scenario 4) & $1.037 \pm 0.040$ & 0.2 & 1.279 \\
Mean intercept of 1, 2, and 3 (scenario 5) & $0.969 \pm 0.038$ & 0.574 & 1.212 \\
\hline
\end{tabular}

${ }^{\mathrm{a}}$ The results show the linear correlation between the total OH columns from MLS + GEOS-Chem and TMF in Figure 11. The orthogonal linear fits weight both error bars in $x$ and $y$ directions. The minimum $\chi_{\text {reduced }}^{2}$ for scenarios 1,2 , and 3 are marked in the contour mapping in Figure 12. The distributions of $\chi_{\text {reduced }}{ }^{2}$ with the change of slope (at fixed intercept) and the change of intercept (at fixed slope) for scenarios 2, 3, 4, and 5 are shown in Figure 13. 


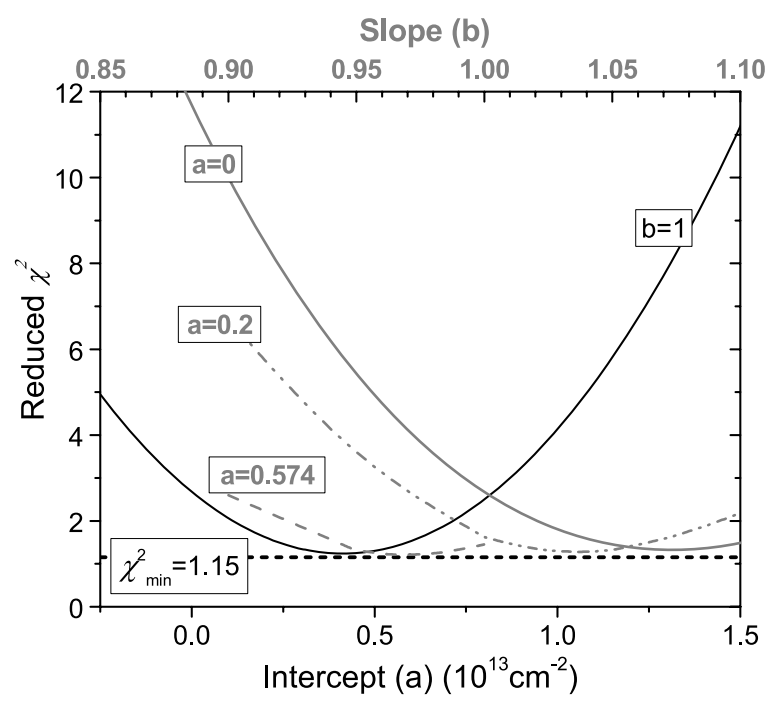

Figure 13. Two-dimensional schematics of the distribution of reduced $\chi^{2}$ with the change of slope $(b)$ or intercept (a) in the orthogonal linear fit (Figure 11). The fit with no constraint (scenario 1) generates a minimum reduced $\chi_{\text {min }}^{2}$ of 1.15 (thick black dotted line). The black curve shows the distribution of reduced $\chi^{2}$ with the change of the intercept $(a)$ when the slope $(b)$ is constrained to 1 (the bottom axis). The minimum is found at an intercept of 0.414 . The gray curves show the distribution of reduced $\chi^{2}$ with the change of the slope $(b)$ when the intercept $(a)$ is constrained to certain values (the top axis). The gray solid curve indicates results with the intercept constrained to 0 . The minimum in the gray dashed-twice-dotted curve is the fit with the intercept constrained to the optimal value 0.2 , while the minimum in the gray dash curve shows the fit with the intercept being 0.574, the mean value from three orthogonal fits. The detailed results are listed in Table 4.

[53] Various statistical approaches to analyze the correlation between the two data sets result in slopes ranging from 0.835 to 1.073 and intercepts from 0.2 to $1.308 \times 10^{13} \mathrm{~cm}^{-2}$. The mean orthogonal fit, which is the best overall representation of the correlation, gives a slope of 0.969 . This implies that if FTUVS measurements at TMF are taken as the reference for the long-term average total $\mathrm{OH}$ column abundance and if model estimates of $\mathrm{OH}$ below $21.5 \mathrm{hPa}$ are accurate within $30 \%$, MLS partial OH columns above $21.5 \mathrm{hPa}$ at $\mathrm{TMF}$ location over a period of near 3 years are statistically accurate within $3.1 \%$.

[54] The comparisons shown in this paper serve as an important validation of MLS measurements of $\mathrm{OH}$ at midlatitudes, with respect to FTUVS measurements of total $\mathrm{OH}$ abundance at TMF from 2004 to 2007.

[55] Acknowledgments. We acknowledge the support of the NASA Upper Atmosphere Research, Aura Validation, Solar Occultation Satellite Science, and Tropospheric Chemistry Programs, the NASA Undergraduate Student Research Program (USRP) and the Caltech Summer Undergraduate Research Fellowship (SURF) program. We also wish to thank King Fai Li and Run-Lie Shia (Caltech) for helpful discussions. Alyn Lambert (JPL) is kindly acknowledged for helping with the orthogonal linear fit. Work at the Jet Propulsion Laboratory, California Institute of Technology, is under contract to the National Aeronautics and Space Administration.

\section{References}

Benkovitz, C. M., et al. (1996), Global gridded inventories of anthropogenic emissions of sulfur and nitrogen, J. Geophys. Res., 101(D22), 29,239-29,253, doi:10.1029/96JD00126

Bey, I., et al. (2001), Global modeling of tropospheric chemistry with assimilated meteorology: Model description and evaluation, J. Geophys. Res., 106(D19), 23,073-23,095, doi:10.1029/2001JD000807.

Bloss, W. J., et al. (2005), The oxidative capacity of the troposphere: Coupling of field measurements of $\mathrm{OH}$ and a global chemistry transport model, Faraday Discuss., 130, 425-436, doi:10.1039/b419090d.

Burnett, C. R., and E. B. Burnett (1996), The regime of decreased $\mathrm{OH}$ vertical column abundances at Fritz Peak Observatory, CO: 19911995, Geophys. Res. Lett., 23(15), 1925-1927, doi:10.1029/96GL01811.

Cageao, R. P., et al. (2001), High-resolution Fourier-transform ultravioletvisible spectrometer for the measurement of atmospheric trace species: Application to OH, Appl. Opt., 40(12), 2024-2030, doi:10.1364/ AO.40.002024.

Canty, T., et al. (2006), Stratospheric and mesospheric HOx: Results from Aura MLS and FIRS-2, Geophys. Res. Lett., 33, L12802, doi:10.1029/ 2006GL025964.

Cheung, R., et al. (2008), An improved method for retrieving hydroxyl radical $(\mathrm{OH})$ abundances from ultraviolet spectra, Appl. Opt., in press.

Duncan, B. N., et al. (2003), Interannual and seasonal variability of biomass burning emissions constrained by satellite observations, J. Geophys. Res., 108(D2), 4100, doi:10.1029/2002JD002378.

Froidevaux, L., et al. (2006), Early validation analyses of atmospheric profiles from EOS MLS on the Aura satellite, IEEE Trans. Geosci. Remote Sens., 44(5), 1106-1121, doi:10.1109/TGRS.2006.864366.

Hudman, R. C., et al. (2007), Surface and lightning sources of nitrogen oxides over the United States: Magnitudes, chemical evolution, and outflow, J. Geophys. Res., 112, D12S05, doi:10.1029/2006JD007912.

Iwagami, N., et al. (1998), Doppler detection of hydroxyl column abundance in the middle atmosphere: Part 2. Measurement for three years and comparison with a 1-D model, J. Atmos. Chem., 29(2), 195-216, doi:10.1023/A:1005928612004

Leblanc, T., and I. S. McDermid (2000), Stratospheric ozone climatology from lidar measurements at Table Mountain $\left(34.4^{\circ} \mathrm{N}, 117.7^{\circ} \mathrm{W}\right)$ and Mauna Loa $\left(19.5^{\circ} \mathrm{N}, 155.6^{\circ} \mathrm{W}\right), J$. Geophys. Res., 105, 14,613-14,623.

Li, K.-F., et al. (2005), OH column abundance over Table Mountain Facility, California: AM-PM diurnal asymmetry, Geophys. Res. Lett., 32, L13813, doi:10.1029/2005GL022521.

Mills, F. P., et al. (2002), OH column abundance over Table Mountain Facility, California: Annual average 1997-2000, Geophys. Res. Lett., 29(15), 1742, doi:10.1029/2001GL014151.

Mills, F. P., et al. (2003), OH column abundance over Table Mountain Facility, California: Intra-annual variations and comparisons to model predictions for 1997-2001, J. Geophys. Res., 108(D24), 4785, doi:10.1029/2003JD003481.

Minschwaner, K., et al. (2003), Hydroxyl column abundance measurements: PEPSIOS instrumentation at the Fritz Peak Observatory and data analysis techniques, J. Atmos. Sol. Terr. Phys., 65, 335-344, doi:10.1016/S1364-6826(02)00297-3.

Müller, R., R. J. Salawitch, P. J. Crutzen, W. A. Lahoz, G. L. Manney, and R. Toumi (1999), Upper Stratospheric Processes: 1998, edited by D. L. Albritton et al., pp. 6.1 -6.44, World Meteorol. Organ., Geneva, Switzerland.

Olivier, J. G. J., and J. J. W. Berdowski (2001), Global emission sources and sinks, in The Climate System, edited by J. Berdowski et al., pp. $33-$ 78, Taylor and Francis, Philadelphia, Pa.

Osterman, G. B., et al. (1997), Balloon-borne measurements of stratospheric radicals and their precursors: Implications for the production and loss of ozone, Geophys. Res. Lett., 24(9), 1107-1110, doi:10.1029/97GL00921.

Pickett, H. M. (2006), Microwave Limb Sounder THz module on Aura, IEEE Trans. Geosci. Remote Sens., 44(5), 1122-1130, doi:10.1109/ TGRS.2005.862667.

Pickett, H. M., et al. (2006), Validation of Aura MLS HOx measurements with remote-sensing balloon instruments, Geophys. Res. Lett., 33, L01808, doi:10.1029/2005GL024048.

Pickett, H. M., et al. (2008), Validation of Aura Microwave Limb Sounder $\mathrm{OH}$ and HO2 Measurements, J. Geophys. Res., 113, D16S30, doi:10.1029/2007JD008775.

Press, W. H., et al. (1992), Numerical Recipes in C: The Art of Scientific Computing, 2nd ed., Cambridge Univ. Press, New York.

Reed, B. C. (1989), Linear least-squares fits with errors in both coordinates, Am. J. Phys., 57(7), 642-646, doi:10.1119/1.15963.

Reed, B. C. (1992), Linear least-squares fits with errors in both coordinates. II: Comments on parameter variances, Am. J. Phys., 60(1), 59-62, doi:10.1119/1.17044.

Rohrer, F., and H. Berresheim (2006), Strong correlation between levels of tropospheric hydroxyl radicals and solar ultraviolet radiation, Nature, 442, $184-187$, doi:10.1038/nature04924. 
Salawitch, R. J., et al. (1994), The diurnal variation of hydrogen, nitrogen, and chlorine radicals: Implications for the heterogeneous production of HNO2, Geophys. Res. Lett., 21(23), 2551-2554, doi:10.1029/ 94GL02782.

Salawitch, R. J., et al. (2005), Sensitivity of ozone to bromine in the lower stratosphere, Geophys. Res. Lett., 32, L05811, doi:10.1029/ 2004GL021504

Schneider, H. R., D. B. A. Jones, M. B. McElroy, and G. Y. Shi (2000), Analysis of residual mean transport in the stratosphere: 1. Model description and comparison with satellite data, J. Geophys. Res., 105(D15), $19,991-20,011$

Waters, J. W., et al. (2006), The Earth Observing System Microwave Limb Sounder (EOS MLS) on the Aura Satellite, IEEE Trans. Geosci. Remote Sens., 44(5), 1075-1092, doi:10.1109/TGRS.2006.873771.

Wennberg, P. O., et al. (1995), In situ measurements of OH and HO2 in the upper troposphere and stratosphere, J. Atmos. Sci., 52(19), 3413-3420, doi:10.1175/1520-0469(1995)052<3413:ISMOOA>2.0.CO;2.

Wennberg, P. O., et al. (1998), Hydrogen radicals, nitrogen radicals, and the production of O3 in the upper troposphere, Science, 279(5347), 49-53, doi:10.1126/science.279.5347.49.
Wu, S., et al. (2007), Why are there large differences between models in global budgets of tropospheric ozone?, J. Geophys. Res., 112, D05302, doi:10.1029/2006JD007801.

York, D. (1966), Least-squares fitting of a straight line, Can. J. Phys., 44, $1079-1086$.

T. Canty, Department of Atmospheric and Oceanic Science, University of Maryland, College Park, MD 20742, USA.

R. Cheung and Y. L. Yung, Division of Geological and Planetary Sciences, California Institute of Technology, MC 170-25, 1200 East California Boulevard, Pasadena, CA 91125, USA.

B. Drouin, Q. Li, H. M. Pickett, T. J. Pongetti, S. P. Sander, C. Shim, and S. Wang, Jet Propulsion Laboratory, California Institute of Technology, 4800 Oak Grove Drive, Pasadena, CA 91109, USA. (shuhui.wang@jpl. nasa.gov)

K. W. Jucks, Harvard-Smithsonian Center for Astrophysics, 60 Garden Street, Cambridge, MA 02138, USA.

R. J. Salawitch, Department of Atmospheric and Oceanic Science and Department of Chemistry and Biochemistry, University of Maryland, College Park, MD 20742, USA. 